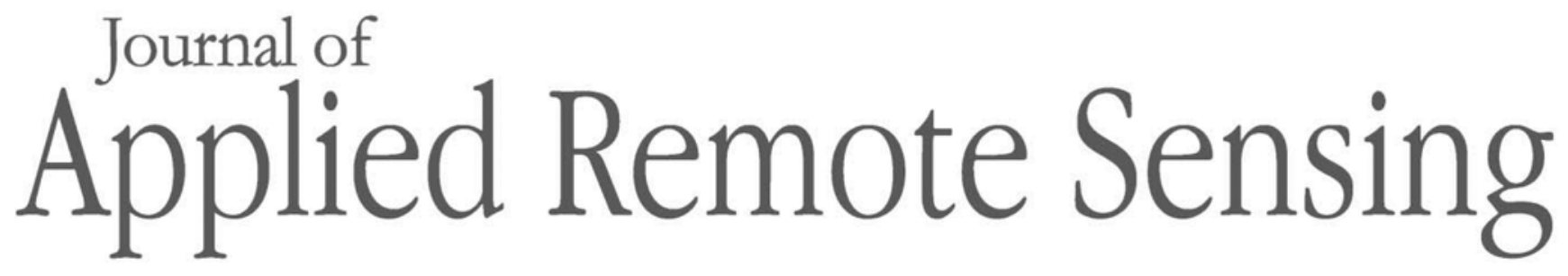

RemoteSensing.SPIEDigitalLibrary.org

\title{
Estimating biomass in temperate grassland with high resolution canopy surface models from UAV- based RGB images and vegetation indices
}

\author{
Ulrike Lussem \\ Andreas Bolten \\ Jannis Menne \\ Martin Leon Gnyp \\ Jürgen Schellberg \\ Georg Bareth
}

Ulrike Lussem, Andreas Bolten, Jannis Menne, Martin Leon Gnyp, Jürgen Schellberg, Georg Bareth, "Estimating biomass in temperate grassland with high resolution canopy surface models from 


\title{
Estimating biomass in temperate grassland with high resolution canopy surface models from UAV-based RGB images and vegetation indices
}

\author{
Ulrike Lussem, ${ }^{\mathrm{a}, *}$ Andreas Bolten, ${ }^{\mathrm{a}}$ Jannis Menne, ${ }^{\mathrm{a}}$ Martin Leon Gnyp, ${ }^{\mathrm{b}}$ \\ Jürgen Schellberg, ${ }^{\mathrm{c}}$ and Georg Bareth ${ }^{\mathrm{a}}$ \\ ${ }^{a}$ University of Cologne, Institute of Geography, GIS and Remote Sensing Group, \\ Cologne, Germany \\ ${ }^{b}$ Research Center Hanninghof, Yara International ASA, Dülmen, Germany \\ ${ }^{c}$ University of Bonn, Institute of Agricultural Ecology, Bonn, Germany
}

\begin{abstract}
Monitoring grassland biomass throughout the growing season is of key importance in sustainable, site-specific management decisions. Precision agriculture applications can support these decisions. However, precision agriculture relies on timely and accurate information on plant parameters with a high spatial and temporal resolution. The use of structural and spectral features derived from unmanned aerial vehicle (UAV)-based image data from low-cost sensors is a promising nondestructive approach to assess plant traits such as above-ground biomass or plant height. Therefore, the main objectives were (1) to evaluate the potential of low-cost UAV-based canopy surface models to monitor sward height as an indicator of grassland biomass, (2) to evaluate the potential of vegetation indices from low-cost UAV-based red-greenblue (RGB) digital image data, and (3) to compare the mentioned methods with established methods for biomass monitoring such as rising plate meters and spectroradiometer-based narrowband vegetation indices over the growing season in 2017, including three cuts. We compared the accuracy of each single UAV-based height feature and vegetation index using a combined multivariate approach to estimate fresh and dry biomass. The heterogeneous sward structure with high spatiotemporal variability led to varying performance in biomass estimation depending on the growths (time between two cuts) and choice of predictor variable. The results showed that biomass prediction by height features provided moderate-to-good results (cross-validation $R^{2}=0.57$ to 0.73 for dry biomass and 0.43 to 0.79 for fresh biomass), but reference measurements based on rising plate meters were more robust when estimating biomass. The spectral features (RGB-based vegetation indices and spectroradiometerbased vegetation indices) yielded varying accuracy and suitability for biomass prediction. Despite the variability, our findings indicate a promising approach for grassland biomass monitoring. (c) The Authors. Published by SPIE under a Creative Commons Attribution 4.0 Unported License. Distribution or reproduction of this work in whole or in part requires full attribution of the original publication, including its DOI. [DOI: 10.1117/1.JRS.13.034525]
\end{abstract}

Keywords: unmanned aerial system; remotely piloted aircraft systems; forage; plant height; biomass; grassland; canopy surface model; spectral; vegetation index.

Paper 190284 received Apr. 15, 2019; accepted for publication Aug. 20, 2019; published online Sep. 23, 2019.

\section{Introduction}

Grasslands cover about $40 \%$ of the earth's terrestrial surface and thereby perform significant ecosystem functions, such as carbon sequestration, ${ }^{1}$ and so are economically important. ${ }^{2} \mathrm{~A}$ wide range of grasslands, such as intensive and extensive pastures and hay and silage meadows, are the basis of the world's meat and milk production and of biofuel production and fibers. ${ }^{3}$ Of key importance in understanding the high spatio-temporal dynamics of cultivated and natural grasslands and adjusting management decisions is the monitoring of quantity and quality of

*Address all correspondence to Ulrike Lussem, E-mail: ulrike.lussem@uni-koeln.de 
above-ground biomass. ${ }^{4}$ Above-ground grass biomass is strongly correlated to canopy height. ${ }^{5-8}$ Canopy height is, thus, an important parameter in management decisions related to grasslands such as grazing rotation or harvesting time.${ }^{8-10}$ Furthermore, precision agriculture applications, such as site-specific fertilizer applications, rely on plant parameter data with a high spatial and temporal resolution. ${ }^{4,10}$ While traditional destructive field measurement techniques (e.g., clipping and weighing) are widely applied in daily farming practice, they are time-consuming, laborintensive, and limited in characterizing the spatial variability of sward characteristics, an indicator of grassland biomass. ${ }^{8,11}$ Since the 1960 s, a range of commercially adapted applications have been developed to nondestructively measure grassland biomass. The simplest forms of handheld devices are pasture rulers (or sward sticks), which measure the uncompressed sward height. Rising plate or disk meters (RPMs) measure the compressed sward height by integrating sward height and density over a defined area using a weighted disk. ${ }^{9,12}$ Several studies have proven that RPM-based compressed sward height is also a robust predictor for grassland biomass. ${ }^{5,8,13}$

With technological development in recent decades, these devices have become more sophisticated. Devices such as the GrassHopper (TrueNorth Technologies, Shannon, Ireland) or GrassOmeter (Monford AG Systems Ltd., Dublin, Ireland) utilize ultrasonic distance sensors that can be mounted on a stick or boot. In addition to handheld devices, sensors such as the Pasture Meter (C-Dax Agricultural Solutions, Palmerston North, New Zealand) or the Pasture Reader (Naroaka Enterprises, Narracan, Australia) are mounted at the rear or front of a vehicle to measure plant height using a tunnel-like sensor equipped with an optical array or an ultrasonic measurement device, respectively. In addition to systems providing structural measures of the sward, biomass can also be assessed using optical sensing systems in the visible to near-infrared spectral region, such as the Yara N-Sensor (Yara ASA, Oslo, Norway) or the GreenSeeker (Trimble Inc., Sunnyvale, California, USA), both handheld or tractor-mounted. These sensors allow direct data logging and transfer and are linked with global navigation satellite systems to create yield maps.

Those sensing systems provide good estimates of sward height or biomass. However, some challenges still remain for precision grassland management or large-scale grassland ecosystem monitoring: (1) limited spatial coverage, especially for handheld devices, and therefore limitations in characterizing within-field spatial variability of the sward, (2) necessity for heavy technical equipment, (3) limited access to the field due to grazing animals or protected species, and, for the vehicle-mounted sensors, potential disturbances at higher frequency for repeated measurements, and finally (4) limitations of applicability depending on field conditions (e.g., slope and soil moisture). ${ }^{6}$

Remote sensing methods offer a potential for rapid and automated measurements of plant parameters, such as biomass, nitrogen or chlorophyll content, in high spatial and temporal resolution on a variety of spatial scales, especially for agricultural applications. These methods include digital imaging (hyperspectral, multispectral, RGB, radar), photogrammetry, laser scanning, and combinations of various sensors on different platforms. ${ }^{14,15}$ Numerous studies have investigated using satellite remote sensing to estimate plant parameters. They derived crop biomass from spectral information of canopy reflectance. ${ }^{14-19}$ However, most satellite systems with high spatial resolution $(<5 \mathrm{~m})$ are operated commercially, and thus the costs of image acquisition for short revisit times can become a constraining factor. ${ }^{20}$

The rapid development of sensor and platform technology, especially in the field of unmanned aerial vehicles (UAVs), and of small high-resolution camera systems (standard RGB, multispectral, or hyperspectral) has opened up applications that support tasks in experimental fields and large farm areas, especially tasks related to precision grassland management and ecosystem monitoring. ${ }^{9,21}$ In addition, the use of these technologies has been accelerated by a rapid development of user-friendly computer programs for three-dimensional scene reconstruction from aerial imagery by Structure-from-Motion (SfM) and Multi-ViewStereopsis (MVS) algorithms. ${ }^{22}$ Especially the flexible application of UAVs has benefitted agricultural monitoring approaches with high spatial and temporal resolution and multiple sensors. $^{23}$ 
In recent years, structural plant parameters, such as plant height, have become the focus of UAV-based remote sensing approaches for crop monitoring. Plant height derived from multitemporal canopy surface models (CSMs) has been studied as a robust estimator of biomass. ${ }^{24-28}$ In addition, crop biomass has been estimated from spectral information from UAV-based standard RGB and multispectral or hyperspectral cameras. ${ }^{29-34}$ Furthermore, some studies have investigated combining structural and spectral features from ground-based or UAV-based sensors to estimate crop parameters. ${ }^{7,24,35-38}$

Those approaches have mainly been adopted to monitor arable crops, where spatial heterogeneity is often lower than in grasslands, ${ }^{10}$ which typically has a high spatio-temporal heterogeneity as a result of the considerably different floristic compositions and the co-occurrence of different phenological stages. This heterogeneity poses challenges in remote sensing-based estimation of biomass quantity and quality. ${ }^{39}$ Some studies have faced these challenges by deploying ground-based measurements using ultrasonic sensors, ${ }^{39,40}$ light detection and ranging, ${ }^{41,42}$ or a combination of structural and spectral features. ${ }^{7,36,39,43,44}$ Furthermore, a few studies have been published on deploying structural features such as height or volume derived from UAV-based camera systems for grassland height or biomass estimation. ${ }^{6,28,36,45-48}$ However, to our knowledge, no study has utilized low-cost UAV-system-based sward height and vegetation indices (VIs) to estimate grassland biomass for at least one entire growing season with three consecutive growths in mid-latitude Europe.

Therefore, the main objectives of the present study are (1) to evaluate the potential of low-cost UAV-based CSMs to monitor sward height as an indicator of biomass, (2) to evaluate the potential of VIs from low-cost UAV-based RGB digital image data, and (3) to compare those methods with established methods for biomass monitoring such as RPMs and spectroradiometerbased narrowband VIs.

\section{Data and Methods}

\subsection{Study Site}

The study was conducted in 2017 on an experimental grassland site in Ersdorf ( $\mathrm{N} 50^{\circ} 34^{\prime} 56.4^{\prime \prime}$, E $6^{\circ} 59^{\prime} 21.1^{\prime \prime}$ ) on the Campus Klein-Altendorf research facility of the Rheinische Friedrich Wilhelms University Bonn, Germany. The site is about $320 \mathrm{~m}$ above mean sea level and has a southeast exposition. The experimental site was established in March 2014 as a nitrogen fertilizer gradient experiment to develop a high range in biomass and plant height of perennial ryegrass (Lolium perenne). Further species are also present such as foxtail grass (Alopecurus sp.), timothy-grass (Phleum pratense) and clover (Trifolium sp.), and to a small amount dandelion (Taraxum officinale) and cocksfoot (Ranunculus sp.). The vegetation type was identified as a typical Lolio-Cynosuretum. The percentage contribution of species was limited so that dominance of species did not change significantly and the vegetation type remained the same.

The experimental setup comprised three growths with four cuts (including one equalization cut in early March) within one year, and the plots were set up in six fertilizer levels with three replicates, resulting in 162 plots of $1.5 \times 3 \mathrm{~m}$ gross area (see Fig. 1). The plots were separated by $20-\mathrm{cm}$-wide border strips treated with herbicide. Calcium ammonium nitrate fertilizer $\left(\mathrm{CaH}_{4} \mathrm{~N}_{4} \mathrm{O}_{9}, 27 \% \mathrm{~N}\right)$ was applied at the beginning of each growth. Thus, six fertilizer levels were established from 0 to $500 \mathrm{~kg} \mathrm{~N} \mathrm{ha}^{-1}$ in increments of $100 \mathrm{~kg} \mathrm{Nha}^{-1}$. Unfortunately, the, at-times, high activity of moles and the common vole disturbed parts of the sward significantly in several plots of replicate 1 (N1, N2, N5, N6) and replicate 2 (N4) (see Figs. 1 and 2).

The soil type was classified as a stagnosol (soil textural classes: silty clay loam/clay loam/ clay). The annual precipitation in 2017 was $598.5 \mathrm{~mm}$ and the mean annual temperature was $10.8^{\circ} \mathrm{C}$. Figure 3 displays the monthly mean precipitation and temperature for 2017 along with the long-term monthly means (1956 to 2015). April, May, and June of 2017 were hotter and dryer than the long-term averages. 


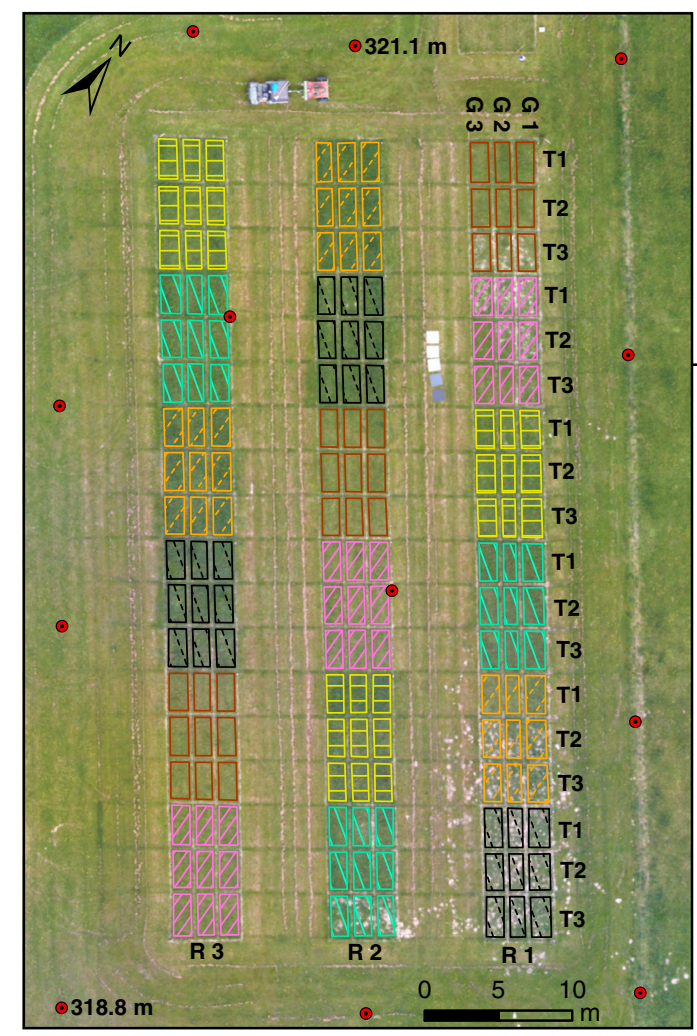

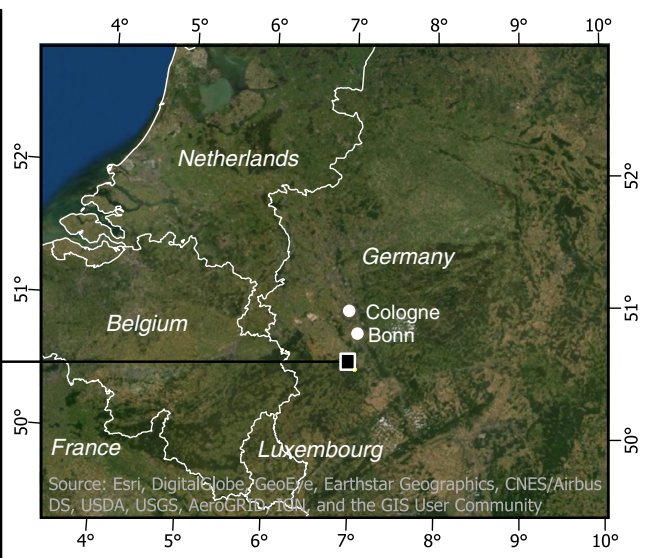

Campus Klein-Altendorf Grassland experiment 2017

Treatments

N1: $0 \mathrm{~kg} \mathrm{~N}$ / ha $N 4: 300 \mathrm{~kg} \mathrm{~N} /$ ha
N2: $100 \mathrm{~kg} \mathrm{~N} / \mathrm{ha}$ N5: $400 \mathrm{~kg} \mathrm{~N} / \mathrm{ha}$
N3: $200 \mathrm{~kg} \mathrm{~N}$ / ha $\because \mathrm{N} 6: 500 \mathrm{~kg} \mathrm{~N} / \mathrm{ha}$

- Ground Control Points

Background:

Orthomosaic by U. Lussem (2017-04-26)

Coordinate System: WGS 1984 UTM Zone 32N

Fig. 1 Location of the experimental site at the Campus Klein-Altendorf. The UAV-based orthomosaic in the detailed map of the experimental site was taken on the first sampling date of the first growth (April 26, 2017). Two exemplary heights of the GCPs show a slight slope. R, replicate; T1 to T3, sampling date 1 to 3 per growth and treatment; e.g. plot T1 in G2 was sampled on the first sampling date of the second growth.
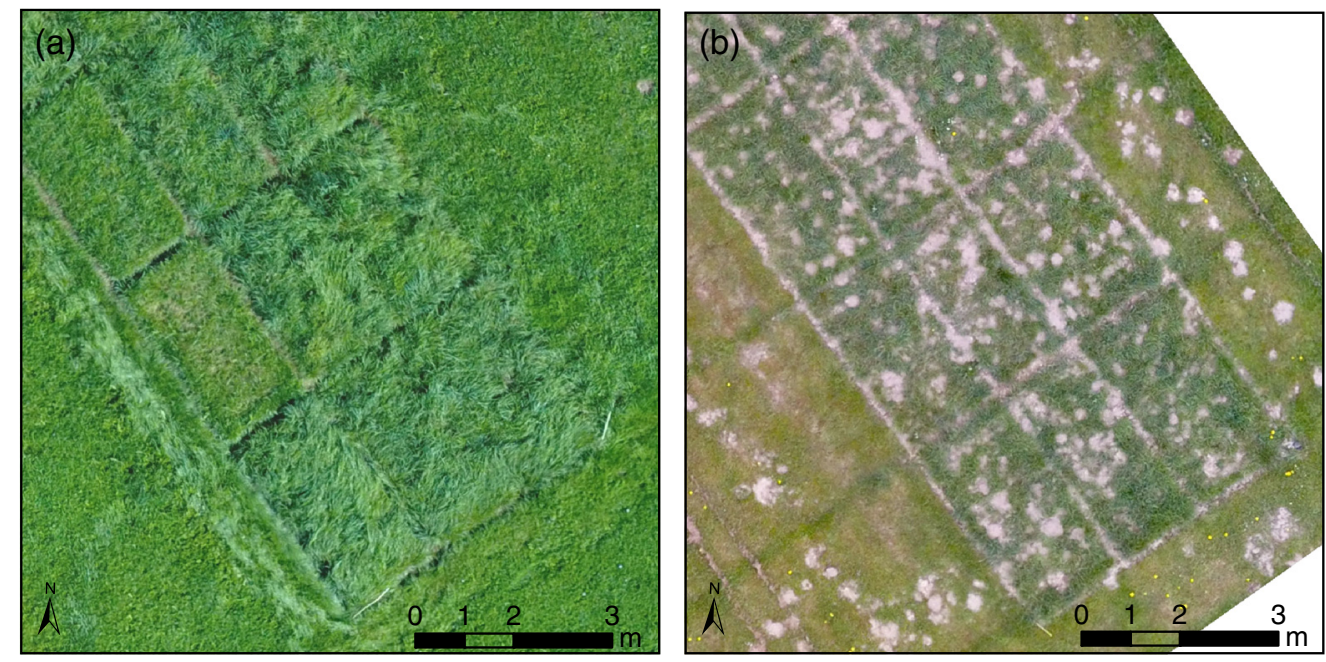

Fig. 2 Close-up view (a) of swards with bent stalks due to vigorous growth in plots of replicate 2 treatment N5 (orthomosaic from August 22, 2017) and (b) of plots in replicate 1 with high rodent activity (orthomosaic from April 26, 2017).

Table 1 lists all sampling dates for the growing season in 2017. For each growth, three sampling dates were scheduled. Data collection included UAV campaigns, spectroradiometer measurements of canopy reflectance, and RPM measurements of compressed sward height and destructive biomass sampling. 

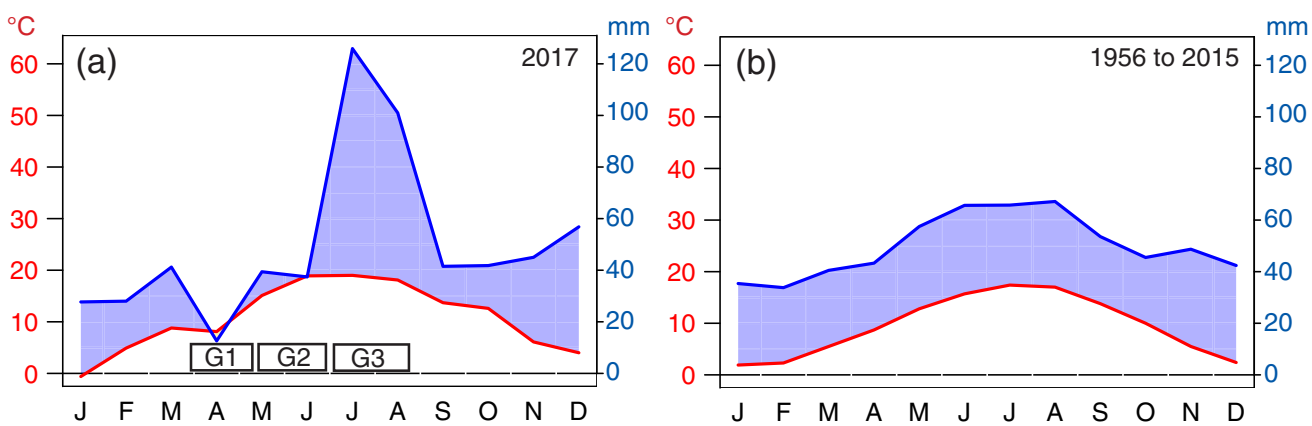

Fig. 3 Monthly temperature $\left({ }^{\circ} \mathrm{C}\right.$ ) and precipitation ( $\mathrm{mm}$ ) averages (a) for 2017 and $(\mathrm{b})$ for the longterm average from 1956 to 2015. G1, G2, and G3 indicate duration of growths in 2017. Data are taken from the local weather station at Campus Klein-Altendorf.

Table 1 Sampling dates for UAV campaigns, reflectance measurements, and reference field data.

\begin{tabular}{|c|c|c|c|c|c|c|}
\hline Growth & Sampling date number & Date & UAV & ASD & RPM & Biomass \\
\hline \multirow[t]{4}{*}{ G1 } & TO & 2017-03-29 & $x$ & - & - & - \\
\hline & T1 & $2017-04-26$ & $x$ & - & $x$ & $x$ \\
\hline & $\mathrm{T} 2$ & $2017-05-03$ & $x$ & x R. 2 and 3 & $x$ & $x$ \\
\hline & T3 & $2017-05-10$ & $x$ & x R. 2 and 3 & $x$ & $x$ \\
\hline \multirow[t]{3}{*}{ G2 } & $\mathrm{T} 1$ & 2017-06-07 & $x$ & $x$ & $x$ & $x$ \\
\hline & T2 & $2017-06-20$ & $x$ & $x$ & $x$ & $x$ \\
\hline & T3 & 2017-06-28 & $x$ & - & $x$ & $x$ \\
\hline \multirow[t]{4}{*}{ G3 } & TO & 2017-07-04 & $x$ & - & - & - \\
\hline & $\mathrm{T} 1$ & 2017-08-02 & $x$ & $x$ & $x$ & $x$ \\
\hline & T2 & 2017-08-09 & $x$ & x R. 2 and 3 & $x$ & $x$ \\
\hline & T3 & $2017-08-22$ & $x$ & $x$ & $x$ & $x$ \\
\hline
\end{tabular}

RPM, rising plate meter; ASD, ASD FieldSpec3; R: replicate; $x /$ - : data/no data; For G1T2, G1T3, and G3T2 only replicates 2 and 3 were measured with the ASD instrument.

\subsection{Reference Field Data and Biomass Sampling}

Reference measurements $\left(\mathrm{SH}_{\mathrm{RPM}}\right)$ of the compressed sward height were taken using a RPM (Platemeter F400, Farmworks Precision Farming Systems Ltd., Feilding, New Zealand). The device uses an electronic digital counter unit to record the compressed sward height per measurement in millimeters and stores each value in an internal memory. The data were downloaded via USB to a paddock management software (P-PLUS, AgHub Ltd., Feilding, New Zealand) and were exported as a .csv file. Five RPM measurements were taken per plot prior to biomass sampling on each date and averaged to represent mean compressed sward height.

A sickle bar mower was used to harvest the biomass of the plots of the respective sampling date directly after each flight campaign. The fresh biomass (FBM) weight for each harvested plot was determined by weighing the clipped biomass per plot. Subsamples of $500 \mathrm{~g} / \mathrm{plot}$ were taken, dried in a forced air drier at $65^{\circ} \mathrm{C}$ to a constant weight and reweighed to determine dry biomass (DBM) yield per unit ground area. Biomass values were upscaled to tons per hectare. Owing to slightly differing plot sizes, the area of each plot was calculated based on a high-resolution UAV-based orthomosaic $(1 \mathrm{~cm} /$ pix: see Sec. 2.3) from the first sampling date (April 26, 2017) and double-checked on site with a tape measure to determine the correct upscaling factor per plot. 


\subsection{Remote Sensing Data Acquisition}

\subsubsection{UAV-based data acquisition}

Image data were collected using a consumer-grade DJI Phantom 4 Advanced (DJI, Shenzhen, China). The UAV's camera had a 1" CMOS sensor with 20 megapixels, a field of view of $84 \mathrm{deg}$ (35 mm equivalent format) and was mounted on a three-axis gimbal (Zenmuse X4S). Waypoint navigation and automated camera triggering were programmed using the DJI-GO App (DJI, Shenzhen, China). The flight was set up as a grid pattern (along- and across-track). The flying height was set to $25 \mathrm{~m}$ and the speed to $1.8 \mathrm{~m} / \mathrm{s}$. Due to software problems, the across-track flight on June 20 had to be flown manually.

Images were captured in 2-s intervals in .jpeg format and saved on an SD card. White balance was set to manual and adjusted to illumination conditions for each sampling date. All flights were performed between 9.30 and 11.30 a.m. CET (solar noon: 12 p.m.) in stable illumination conditions. Forward and lateral image overlaps were $>85 \%$.

Twelve ground control points (GCPs) were installed on-site (see Fig. 1). The targets were plywood boards $(30 \times 30 \mathrm{~cm})$, painted with a black cross on a light-gray background and mounted on wooden poles across the field. The GCPs were measured using a Real Time Kinematic Differential GPS (Topcon HiperPro: Topcon, Tokyo, Japan).

\subsubsection{Field spectroradiometer measurements}

Canopy reflectance of the sward was measured with an ASD FieldSpec3 spectroradiometer (Analytical Spectral Devices, Boulder, Colorado, USA). The ASD FieldSpec3 acquires reflectance in the wavelength range from 350 to $2500 \mathrm{~nm}$ using three detectors: one in the visible-near infrared region (VNIR: 350 to $1000 \mathrm{~nm}$ ) and two for the shortwave-infrared regions (SWIR1: 1001 to 1830 , SWIR2: 1831 to 2500). The fiber optic with a field of view of $25 \mathrm{deg}$ was mounted on an orthogonal suspension rod to ensure fixed viewing geometry for each measurement. The sensor-canopy distance was set to $60 \mathrm{~cm}$, resulting in a footprint diameter of $26.6 \mathrm{~cm}$.

Reflectance measurements with the spectroradiometer were taken directly after each flight campaign (between 11 a.m. and 2 p.m. CET, solar noon: 12 p.m.). Eight reflectance measurements per plot were taken with 10 sample counts per spectra. White reference using a Zenith Lite $^{\mathrm{TM}}$ panel and dark current measurements were taken prior to the next plot.

For the first and second growths, reflectance measurements were only possible on two sampling dates due to unstable weather conditions. Furthermore, for the same reason, on three sampling dates, it was only possible to collect reflectance measurements for two of three replicates (see Table 1). Since the UAV flight time to cover the whole experimental field was only about $10 \mathrm{~min}$, it was possible to acquire image data in stable illumination conditions. In contrast, data acquisition with the ASD instrument took about 1 to $1 \frac{1}{2} \mathrm{~h}$ and, depending on changing cloud cover, was sometimes not possible at all.

\subsection{Remote Sensing Data Processing and Feature Extraction}

\subsubsection{UAV-based data processing and feature extraction}

The image datasets were processed in the SfM software Agisoft Photoscan Professional v1.4 (Agisoft LLC, St. Petersburg, Russia) to obtain digital surface models (DSMs) and orthomosaics, as numerous studies have already demonstrated accurate results. ${ }^{27,49,50}$

Image alignment was run on "low" with camera reference preselection, to place one of the 12 GCPs in at least 10 images, preferably more. Reference accuracy settings were set to $\pm 0.01 \mathrm{~m}$ for GCPs and to $\pm 10 \mathrm{~m}$ for camera positions. After GCP placement, image alignment was run again on "high" quality using 100,000 as the key point limit and 400,000 as the tie point limit. The resulting sparse point clouds were checked for outliers using manual selection. The dense point cloud was computed using high-quality setting and "mild" depth filtering, to preserve the finer details of the grass canopy, based on our own previous tests and as suggested by Cunliffe et al. ${ }^{51}$ 
Table 2 Parameters of image acquisition and processing.

\begin{tabular}{lccccccccc}
\hline \hline G & T & Date & $\begin{array}{c}\text { Number of } \\
\text { images }\end{array}$ & $\begin{array}{c}X \text { error } \\
\mathrm{cm}\end{array}$ & $\begin{array}{c}Y \text { error } \\
\mathrm{cm}\end{array}$ & $\begin{array}{c}Z \text { error } \\
\mathrm{cm}\end{array}$ & $\begin{array}{c}\text { Total } \\
\text { error cm }\end{array}$ & $\begin{array}{c}\text { Reprojection } \\
\text { error pix }\end{array}$ & $\begin{array}{c}\text { Point density } \\
\text { points } / \mathrm{m}^{2}\end{array}$ \\
\hline G1 & T0 & $2017-03-29$ & 284 & 1.82 & 4.69 & 2.47 & 5.60 & 1.72 & 2470 \\
& T1 & $2017-04-26$ & 243 & 2.03 & 4.92 & 2.30 & 5.80 & 1.40 & 2720 \\
& T2 & $2017-05-03$ & 212 & 1.44 & 5.65 & 1.38 & 5.99 & 1.58 & 2500 \\
& T3 & $2017-05-10$ & 245 & 3.35 & 7.32 & 3.36 & 8.72 & 1.50 & 2360 \\
\hline G2 $^{\text {a }}$ & T1 & $2017-06-07$ & 219 & 2.07 & 4.32 & 0.91 & 4.88 & 1.49 & 2320 \\
& T2 & $2017-06-20^{b}$ & 214 & 2.60 & 4.92 & 5.91 & 8.12 & 1.06 & 2180 \\
& T3 & $2017-06-28$ & 210 & 2.00 & 4.79 & 2.10 & 5.60 & 1.49 & 2260 \\
\hline G3 & T0 & $2017-07-04$ & 207 & 2.30 & 4.75 & 0.89 & 5.36 & 1.48 & 2270 \\
& T1 & $2017-08-02$ & 206 & 1.68 & 5.03 & 2.81 & 6.00 & 1.53 & 2550 \\
& T2 & $2017-08-09$ & 206 & 3.51 & 6.01 & 2.45 & 7.38 & 1.49 & 2540 \\
\hline \hline & T3 & $2017-08-22$ & 219 & 2.19 & 4.83 & 4.95 & 7.26 & 1.38 & 2720 \\
\hline \hline
\end{tabular}

Note: $G$, growth; $T$, sampling date number.

${ }^{\mathrm{a}} \mathrm{G} 1-\mathrm{TO}$ was used to create CSM for G2.

${ }^{b}$ Cross-flight was flown manually due to software issues.

Table 2 summarizes the outputs of the error reports generated by Agisoft Photoscan v1.4 for each image dataset. The number of images acquired on each sampling date varies due to the start time of camera triggering and slightly varying speed since the speed was needed to be set manually using a slider bar in the app at the beginning of each flight.

The highest errors calculated from the GCPs were found in the $Y$ axis, with no error lower than 4.32 and up to $7.32 \mathrm{~cm}$. Errors in the $X$ axis were between 1.44 and $3.51 \mathrm{~cm}$, and the errors in the $Z$ axis ranged between 0.91 and $5.91 \mathrm{~cm}$. The highest total errors were reported for G1-T3 and G2-T2. The highest reprojection error was reported on G1-T1 with 1.72 pixels and the lowest for G2-T2 with 1.06 pixels. Point densities ranged between 2180 and 2720 points $/ \mathrm{m}^{2}$.

The dense point cloud was used to compute a DSM and an orthomosaic ("mosaic blending mode") with a spatial resolution of 2 and $1 \mathrm{~cm}$, respectively, both in WGS 1984, UTM Zone $32 \mathrm{~N}$. Subsequent raster file processing was completed in ArcGIS Pro v2.1 (ESRI, Redlands, California, USA).

The workflow described by Bendig et $a .^{49}$ was applied to extract height features. The DSM acquired directly after the equalization cut (T0) was subtracted from the DSM of each sampling date (T1 to T3) per growth to obtain the CSM. Sward height per plot was extracted from each CSM using a polygonal shapefile of the plots $(12.5 \mathrm{~cm}$ inward buffer to account for border effects). The height features included the mean sward height $\left(\mathrm{SH}_{\text {mean }}\right)$ and the 90th percentile of the sward height $\left(\mathrm{SH}_{\mathrm{p} 90}\right)$, since they correlated well with grassland biomass in previous tests and in the studies by Viljanen et al. ${ }^{7}$ and Näsi et al. ${ }^{36}$

The orthomosaic of each sampling date were used to calculate four RGB-based VIs $\left(\mathrm{VI}_{\mathrm{RGB}}\right.$, see Table 3), from the individual bands of the orthomosaics. For each plot per sampling date, the mean value of the VIs was extracted using the same polygonal shapefile as for the height features.

In addition, two composite indices were assessed, the GrassI and the ExcessGreen Index $($ ExGI $)+\mathrm{SH}_{\mathrm{p} 90}$, calculated from one height feature and one $\mathrm{VI}_{\mathrm{RGB}}$. Both indices have performed well in estimating grassland biomass. ${ }^{7}$

The VIs were chosen to be comparable to previous studies that used aerial image data. The Red-Green-Blue Vegetation Index (RGBVI) was tested for barley biomass in Bendig et al.'s 
Table 3 Visible band VIs ( $\mathrm{VI}_{\mathrm{RGB}}$ ) tested in this study. $\mathrm{R}, \mathrm{G}$, and $\mathrm{B}$ are the digital numbers (DNs) of the respective channels red, green and blue; $r, g$, and $b$ are the normalized $D N s$ of the respective channels $(g=G /(R+G+B), r=R /(R+G+B), b=B /(R+G+B)$.

\begin{tabular}{|c|c|c|c|}
\hline Name & & Formula & References \\
\hline Red-Green-Blue Vegetation Index & RGBVI & $\frac{[(G \times G)-(B \times R)]}{[(G \times G)+(B \times R)]}$ & Bendig et al. ${ }^{24}$ \\
\hline Visible Atmospherically Resistant Index & VARI & $\frac{G-R}{G+R-B}$ & Gitelson et al. ${ }^{52}$ \\
\hline Normalized Green Red Difference Index & NGRDI & $\frac{G-R}{G+R}$ & Tucker ${ }^{53}$ \\
\hline Excess Green Index & ExGl & $2 \times g \times r-b$ & Woebbecke et al. ${ }^{54}$ \\
\hline Grassland Index & Grassl & $\mathrm{RGBVI}+\mathrm{SH}_{\text {mean }}$ & Bareth et al. ${ }^{44}$ \\
\hline Excess Green Index and height feature & $\mathrm{ExGI}_{\mathrm{SHp} 90^{\mathrm{a}}}$ & $\mathrm{ExGI}+\mathrm{SH}_{\mathrm{p} 90}$ & Viljanen et al. ${ }^{7}$ \\
\hline
\end{tabular}

aBased on Viljanen et al., the $\mathrm{SH}_{\mathrm{p} 90}$ was selected.

study $^{24}$ and for grassland in Bareth et al.'s study ${ }^{44}$ and showed good-to-moderate results. The Normalized Green Red Difference Index (NGRDI; also known as Green-Red VI) showed good results for grassland biomass in Lussem et al.'s study ${ }^{55}$ for oats in Jannoura et al.'s study, ${ }^{56}$ and for corn and soybean biomass in Hunt et al.'s study. ${ }^{57}$ The Excess Green Index was originally intended to calculate fractional vegetation $\operatorname{cover}^{54}$ but showed good results for grassland biomass estimation. ${ }^{7}$ Gitelson et al. ${ }^{52}$ introduced the Visible Atmospherically Resistant Index (VARI) as an extension of the NGRDI to assess vegetation fraction, but it also showed good results in estimating grassland biomass. ${ }^{55}$

\subsubsection{Field spectroradiometer-derived vegetation indices}

Spectroradiometer measurements were preprocessed in the ASD-software Indico Pro v5.0 (Analytical Spectral Devices, Boulder, Colorado, USA) for sensor offset correction and subsequently processed in the R package "prospectr" ${ }^{58}$ by applying a Savitzky-Golay filter with a second-degree polynomial and a moving window size of 17 to smooth the spectra.

For this study, VIs from the VNIR $\left(\mathrm{VI}_{\mathrm{VNIR}}\right)$ region were tested (see Table 4). The Normalized Difference Vegetation Index (NDVI), Optimized Soil Adjusted Vegetation Index (OSAVI), Renormalized Difference Vegetation Index (RDVI), Red Edge Inflection Point (REIP), and Normalized Difference Red-Edge Index (NDREI) were chosen to be comparable to previous studies. $^{7,36,59-61}$ In addition, the VIs listed in Table 3 were calculated from narrowband data acquired by the ASD (with $670 \mathrm{~nm}$ as red, $550 \mathrm{~nm}$ as green, and $480 \mathrm{~nm}$ as blue band) to evaluate the $\mathrm{VI}_{\mathrm{RGB}}$ obtained by the UAV's camera.

Table 4 VIs from the VNIR region tested in this study $\left(V_{V} I_{V I R}\right) . R=$ Reflectance in percentage of the respective narrowband.

\begin{tabular}{lccc}
\hline \hline Name & & Formula & References \\
\hline Normalized Difference Vegetation Index & NDVI & $\frac{R_{800}-R_{670}}{R_{800}+R_{670}}$ & Rouse et al. ${ }^{62}$ \\
Renormalized Difference Vegetation Index & RDVI & $\frac{\left(R_{798}-R_{670}\right)}{\left(\sqrt{R_{798}+R_{670}}\right)}$ & Roujean and Breon ${ }^{63}$ \\
Optimized Soil Adjusted Vegetation Index & OSAVI & $(1+0.16) \times \frac{\left(R_{800}-R_{670}\right)}{\left(R_{800}+R_{670}+0.16\right)}$ & Rondeaux et al. ${ }^{64}$ \\
Red Edge Inflection Point & REIP & $700+40 \times \frac{\left(\frac{R_{670}+R_{780}}{2}\right)-R_{700}}{\left(R_{770}+R_{700}\right)}$ & Guyot and Baret ${ }^{65}$ \\
Normalized Difference Red Edge Index & NDREI & $\frac{R_{790}-R_{720}}{R_{790}+R_{720}}$ & Gitelson and Merzlyak ${ }^{66}$ \\
\hline \hline
\end{tabular}




\subsection{Statistical Analysis and Evaluation}

Statistical analysis was performed in $\mathrm{R} \mathrm{v3.5.}{ }^{67}$ The sensitivity of each feature was tested using Pearson's Correlation Coefficient (PCC). Bivariate and multivariate linear regression models were established to estimate biomass as a function of the predictor variables. The package "caret" was used for statistical modeling. ${ }^{68,69}$ For the bivariate regression models, each height and VI feature was taken as a predictor of DBM and FBM. For the multivariate linear regression (MLR) models, each VI feature was paired with one of the height features. The data were split based on the three growths and the statistics are reported accordingly.

Prediction accuracy of each predictor variable was quantified using the coefficient of determination $\left(R^{2}\right)$ and root-mean-squared error (RMSE). The performance metrics were calculated using leave-one-out cross-validation (LOO-CV). LOO-CV holds out one sample point as a reference, while the regression model is trained using all remaining samples. This process was repeated $n$ times. The resulting error estimates for $n$ runs were averaged. ${ }^{70}$

\section{Results}

\subsection{Orthomosaics and Canopy Surface Models}

The orthomosaics and CSMs for the three sampling dates of the first growth are presented in Fig. 4. Both display a good visual correlation to the fertilizer treatments and a detailed
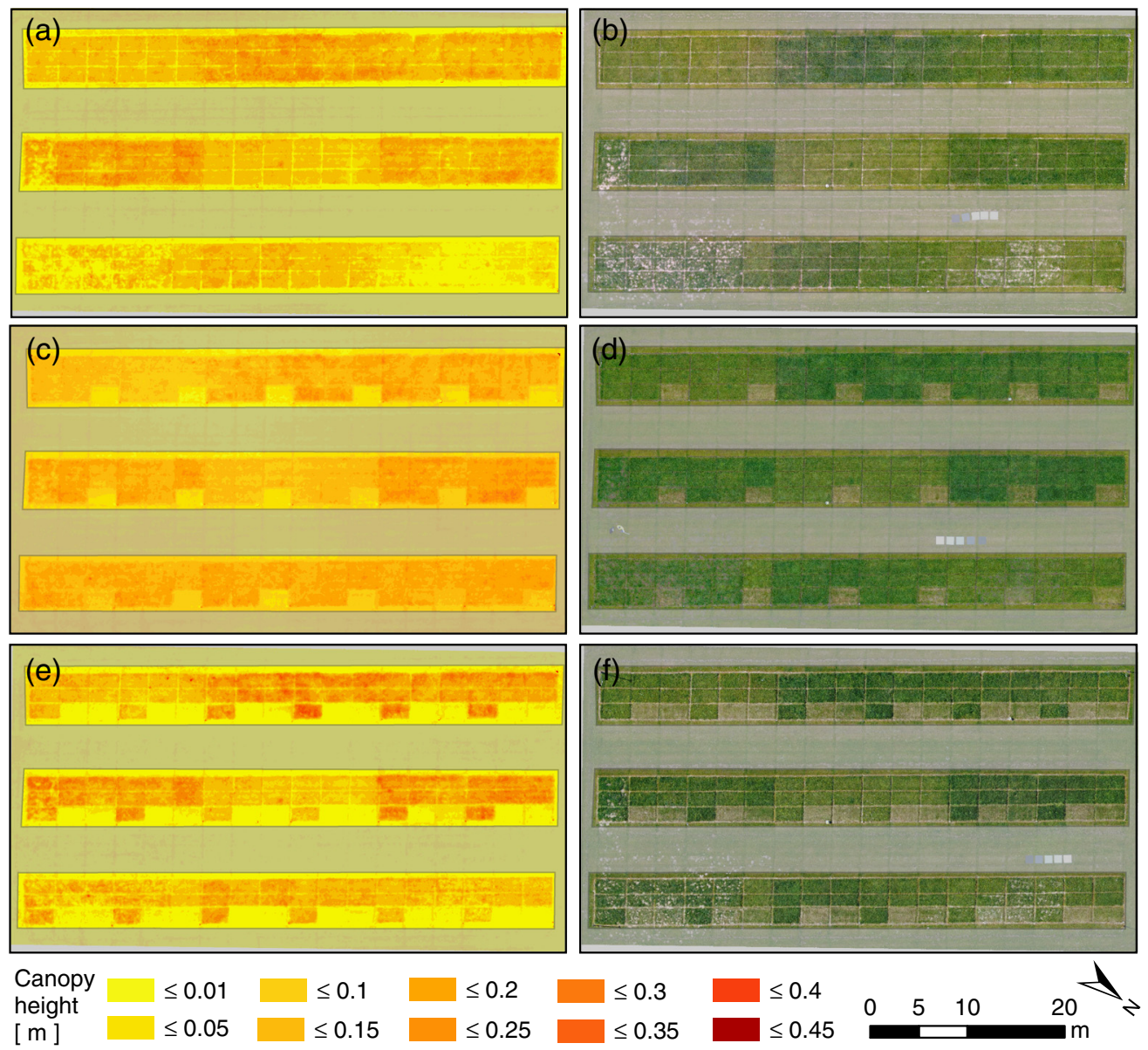

Fig. 4 CSMs (left panels) and orthomosaics (right panels) for the first growth in 2017: (a) and (b) T1 April 26, 2017; (c) and (d) T2 May 3, 2017; (e) and (f) T3 May 10, 2017. Lower sward heights from previously sampled plots or from plots affected by high rodent activity are clearly distinguishable. 
representation of sward height is achieved with high spatial resolution. The disturbances by rodents as mentioned above became visible in the CSMs and orthomosaics. In the orthomosaics of Fig. 4, the effect of a rainfall event on G1-T2 shortly before image acquisition can be seen: the wet soil appears darker than the dry soil on the first and third sampling dates.

\subsection{Reference Measurements}

Due to vigorous growth in G3, grass stalks were slightly lodging in the highest fertilizer treatments (N5 and N6) on G3-T3 (see Fig. 2). Plots with high rodent activity were excluded from the analysis, since they produced outliers with unreasonable biomass values.

Table 5 summarizes the descriptive statistics of the biomass measurements. G1 and G3 yielded the highest biomass values, while G2 was affected by drought and thus had lower tiller density and biomass development.

Table 6 summarizes the descriptive statistics for the RPM sward height reference measurements $\left(\mathrm{SH}_{\mathrm{RPM}}\right)$ and the mean sward height derived from CSM $\left(\mathrm{SH}_{\mathrm{CSM}}\right)$. The $\mathrm{SH}_{\mathrm{CSM}}$ resulted in a higher range of values and a higher standard deviation than the $\mathrm{SH}_{\mathrm{RPM}}$.

Table 5 Descriptive statistics of the biomass measurements for each sampling date per growth. G, growth; T, sampling date number; min, minimum; max, maximum; sd, standard deviation.

\begin{tabular}{|c|c|c|c|c|c|c|c|c|c|c|}
\hline & & \multirow[b]{2}{*}{ Date } & \multicolumn{4}{|c|}{$\mathrm{DBM}_{\text {tha }}{ }^{-1}$} & \multicolumn{4}{|c|}{ FBM tha $^{-1}$} \\
\hline & & & $\min$ & $\max$ & mean & sd & $\min$ & $\max$ & mean & sd \\
\hline \multirow[t]{3}{*}{ G1 } & $\mathrm{T} 1$ & $2017-04-26$ & 1.33 & 2.87 & 2.02 & 0.52 & 4.49 & 10.64 & 7.10 & 2.12 \\
\hline & $\mathrm{T} 2$ & $2017-05-03$ & 1.45 & 3.83 & 2.44 & 0.69 & 5.01 & 15.94 & 9.41 & 3.22 \\
\hline & T3 & $2017-05-10$ & 1.41 & 4.37 & 2.74 & 0.97 & 4.56 & 15.60 & 9.35 & 3.60 \\
\hline \multirow[t]{3}{*}{ G2 } & $\mathrm{T} 1$ & 2017-06-07 & 0.58 & 2.27 & 1.37 & 0.47 & 1.95 & 7.56 & 4.46 & 1.66 \\
\hline & $\mathrm{T} 2$ & $2017-20-06$ & 0.55 & 1.70 & 1.00 & 0.34 & 1.90 & 5.36 & 3.22 & 1.03 \\
\hline & T3 & 2017-06-28 & 1.16 & 2.36 & 1.74 & 0.40 & 4.29 & 9.83 & 6.65 & 1.66 \\
\hline \multirow[t]{3}{*}{ G3 } & $\mathrm{T} 1$ & 2017-08-02 & 0.68 & 2.17 & 1.43 & 0.39 & 2.21 & 9.85 & 5.81 & 2.24 \\
\hline & $\mathrm{T} 2$ & 2017-08-09 & 1.67 & 3.57 & 2.34 & 0.46 & 5.30 & 13.22 & 8.03 & 2.00 \\
\hline & T3 & 2017-08-22 & 2.15 & 4.10 & 3.32 & 0.60 & 6.94 & 16.40 & 11.91 & 2.68 \\
\hline
\end{tabular}

Table 6 Descriptive statistics of the sward height reference measurements (RPM) and mean sward height from CSMs for each sampling date per growth. G, growth; T, sampling date number; min, minimum; max, maximum; sd, standard deviation.

\begin{tabular}{|c|c|c|c|c|c|c|c|c|c|c|}
\hline & & \multirow[b]{2}{*}{ Date } & \multicolumn{4}{|c|}{ Sward height RPM (cm) } & \multicolumn{4}{|c|}{ Mean sward height CSM (cm) } \\
\hline & & & $\min$ & $\max$ & mean & sd & $\min$ & $\max$ & mean & sd \\
\hline \multirow[t]{3}{*}{ G1 } & $\mathrm{T} 1$ & $2017-04-26$ & 8.14 & 13.42 & 10.72 & 1.67 & 2.47 & 14.00 & 9.43 & 3.17 \\
\hline & T2 & $2017-05-03$ & 8.90 & 18.26 & 12.29 & 2.59 & 10.97 & 22.52 & 16.14 & 3.22 \\
\hline & T3 & $2017-05-10$ & 9.84 & 19.10 & 14.87 & 3.34 & 6.20 & 22.41 & 12.88 & 5.12 \\
\hline \multirow[t]{3}{*}{ G2 } & $\mathrm{T} 1$ & $2017-06-07$ & 5.82 & 11.20 & 8.42 & 1.46 & 8.43 & 19.10 & 15.39 & 3.50 \\
\hline & T2 & $2017-20-06$ & 6.18 & 9.36 & 7.27 & 0.92 & 4.74 & 13.66 & 8.31 & 2.84 \\
\hline & T3 & 2017-06-28 & 6.44 & 9.74 & 7.91 & 0.96 & 14.94 & 22.80 & 18.79 & 2.68 \\
\hline \multirow[t]{3}{*}{ G3 } & $\mathrm{T} 1$ & 2017-08-02 & 7.40 & 12.96 & 9.41 & 1.52 & 2.38 & 13.25 & 7.27 & 2.70 \\
\hline & T2 & 2017-08-09 & 8.18 & 13.84 & 10.73 & 1.83 & 10.81 & 18.98 & 14.26 & 2.27 \\
\hline & T3 & $2017-08-22$ & 9.74 & 16.28 & 13.92 & 1.89 & 9.43 & 21.58 & 14.52 & 3.08 \\
\hline
\end{tabular}


Table 7 PCCs for the CSM-derived height features $\left(\mathrm{SH}_{\text {mean }}\right.$ : CSM-based mean sward height, $\mathrm{SH}_{\mathrm{p} 90}$ : CSM-based 90th percentile sward height) and rising plate meter $\left(\mathrm{SH}_{\mathrm{RPM}}\right)$ reference measurements to DBM and FBM for all growths.

\begin{tabular}{|c|c|c|c|c|c|c|}
\hline & \multicolumn{2}{|c|}{ Growth 1} & \multicolumn{2}{|c|}{ Growth 2} & \multicolumn{2}{|c|}{ Growth 3} \\
\hline & DBM & FBM & DBM & FBM & DBM & FBM \\
\hline $\mathrm{SH}_{\mathrm{RPM}}$ & 0.94 & 0.89 & 0.78 & 0.68 & 0.89 & 0.92 \\
\hline $\mathrm{SH}_{\text {mean }}$ & 0.80 & 0.85 & 0.81 & 0.79 & 0.75 & 0.65 \\
\hline $\mathrm{SH}_{\mathrm{p} 90}$ & 0.87 & 0.90 & 0.83 & 0.83 & 0.78 & 0.68 \\
\hline
\end{tabular}

$P<0.001$ for all correlations.

Table 7 lists the PCCs for the CSM-based height features $\mathrm{SH}_{\mathrm{p} 90}$ and $\mathrm{SH}_{\text {mean }}$ and the RPM reference measurements of DBM and FBM. Since the $\mathrm{SH}_{\mathrm{p} 90}$ correlated slightly better than $\mathrm{SH}_{\text {mean }}$ for DBM and FBM, only the $\mathrm{SH}_{\mathrm{p} 90}$ is described in the following section. For completeness, a sensitivity analysis of all single features by growths, by growths and treatment, and by growths and sampling date is included in the Appendix (Tables 12-19).

The relationships between DBM and $\mathrm{SH}_{\mathrm{RPM}}$ and $\mathrm{SH}_{\mathrm{p} 90}$ are displayed in Fig. 5. $\mathrm{SH}_{\mathrm{RPM}}$ shows a strong linear relationship to DBM with little deviation from the regression line for all three growths.
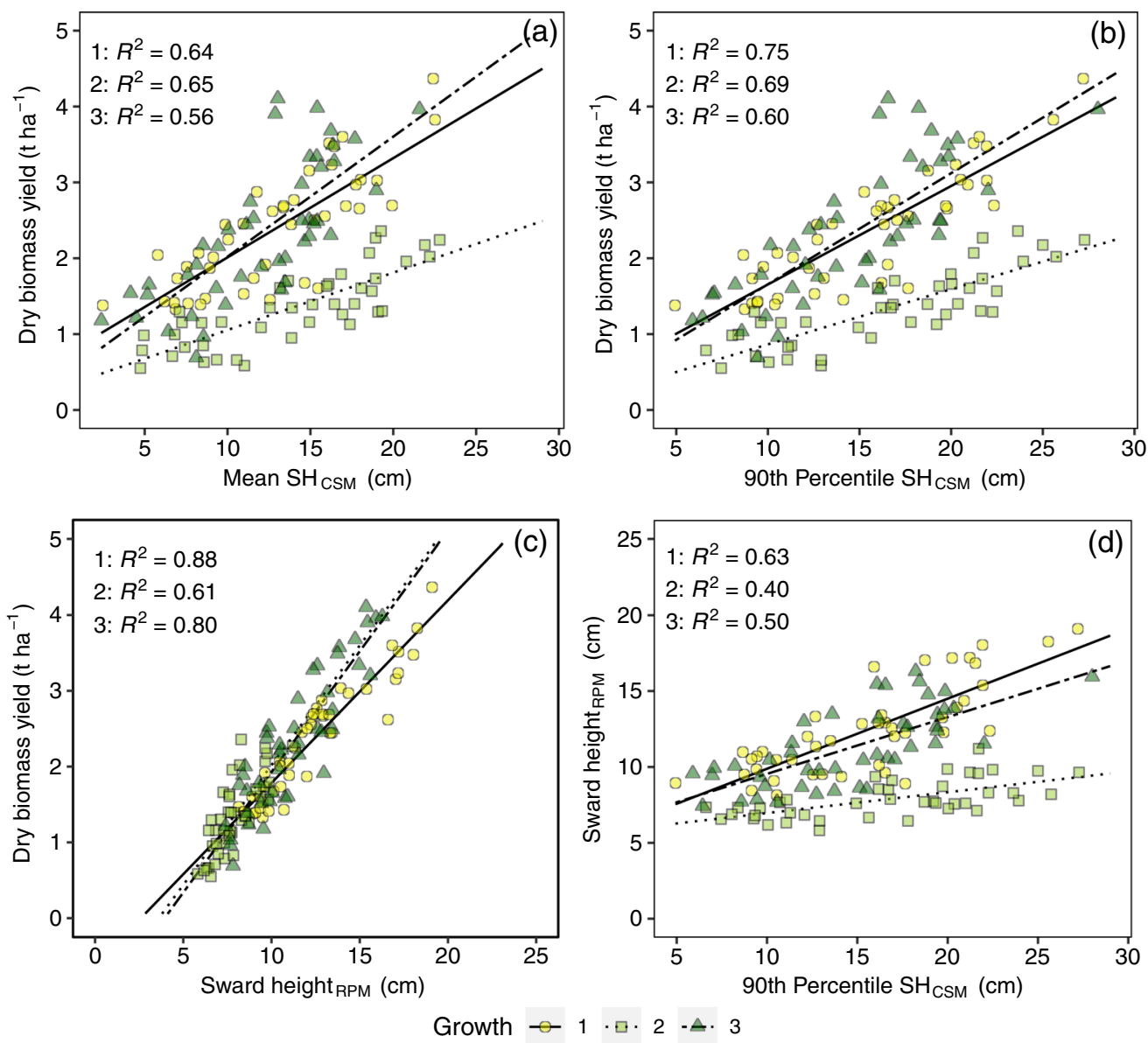

Fig. 5 Scatterplots of (a) mean CSM-based sward height versus DBM yield, (b) 90th percentile CSM-based sward height versus DBM yield, (c) mean RPM-based sward height versus DBM yield, and (d) 90th percentile CSM-based sward height versus mean RPM-based sward height. $P<0.001$ for all correlations. 

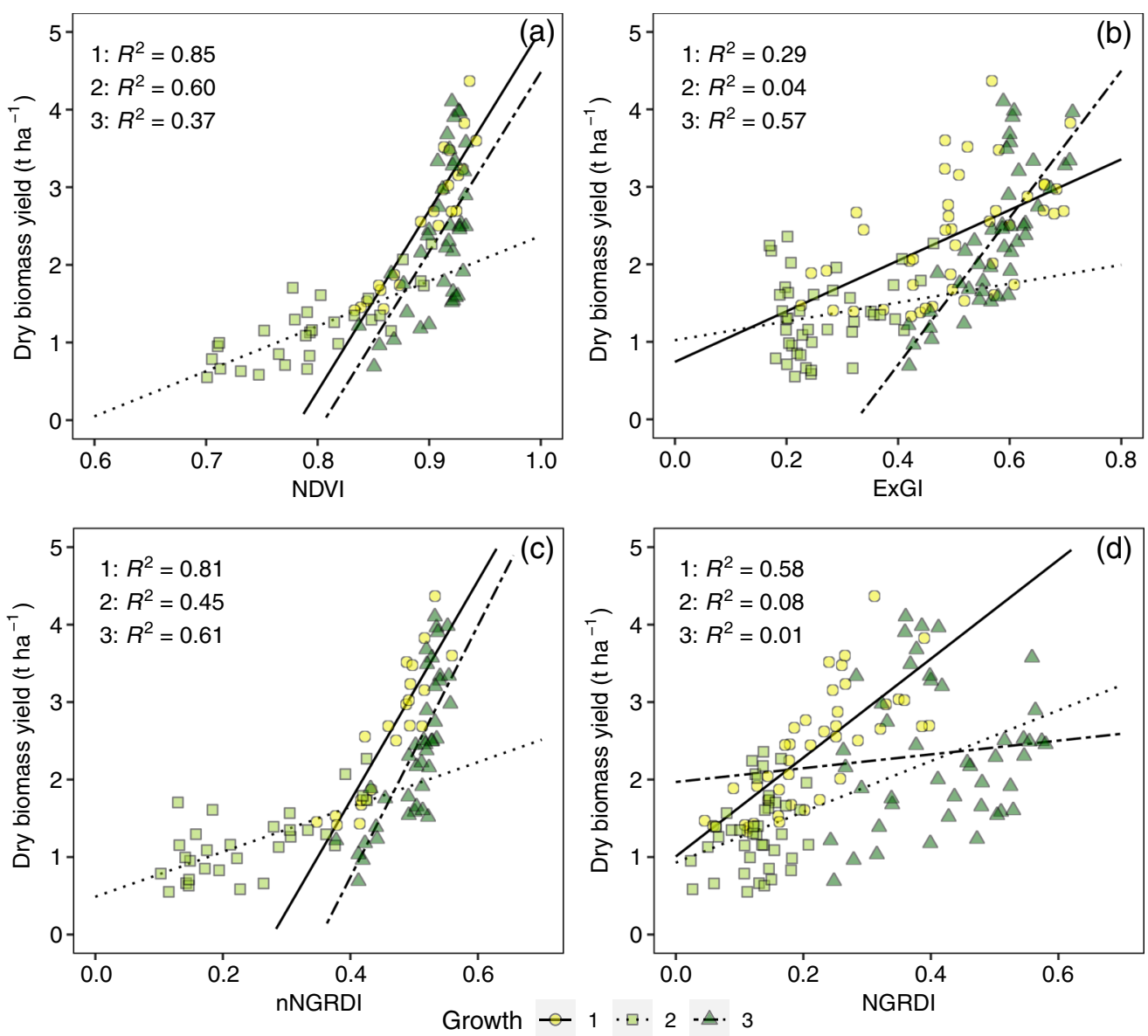

Fig. 6 Scatterplots of selected VIs for all growths: (a) NDVI versus DBM yield $(P<0.001$ for all growths), (b) ExGl versus DBM yield ( $P<0.001,0.208$, and $<0.001$ for $\mathrm{G} 1, \mathrm{G} 2$, and $\mathrm{G} 3$, respectively), (c) ASD-based narrowband NGRDI versus DBM yield ( $P<0.001$ for all growths), and (d) orthomosaic-based NGRDI versus DBM yield $(P<0.001,0.067,0.521$ for G1, G2, and G3, respectively).

The $\mathrm{SH}_{\mathrm{p} 90}$ feature shows larger deviation from the regression line, while the second growth falls outside the pattern of the first and third growths. Nevertheless, the $R^{2}$ for the second growth was higher for $\mathrm{SH}_{\mathrm{p} 90}$, compared to the $\mathrm{SH}_{\mathrm{RPM}} \cdot \mathrm{SH}_{\mathrm{RPM}}$ and $\mathrm{SH}_{\mathrm{p} 90}$ were only moderately well correlated.

Figure 6 presents the relationship between selected VIs and DBM. The UAV-based NGRDI performed moderately well for the first growth with an $R^{2}$ of 0.58 but shows no correlation for the second and third growths. In comparison, the ASD-based nNGRDI performed more consistently for the three growths (see Table 15). Slight lodging of the grass sward in six plots with high fertilizer treatments at G3-T3 led to a higher deviation from the regression line. The spectroradiometer-based NDVI performed moderately well. In comparison to the NGRDI, the ExGI correlated better with DBM in G3 since the slightly lodging sward in six plots of treatments N5 and N6 seemed to have only a minor effect on the ExGI values.

\subsection{Cross-Validation Results of Simple Linear Regression for Estimation of Dry Biomass and Fresh Biomass}

The predictive accuracy of the height features and VIs for biomass estimation was assessed using LOO-CV. Table 8 displays the cross-validation results of the bivariate regression models of $\mathrm{DBM}$ and each feature by growth. The $\mathrm{SH}_{\mathrm{RPM}}$ performed best for $\mathrm{G} 1$ and $\mathrm{G} 3$ in estimating DBM, with an $R^{2}$ of 0.87 (RMSE: $0.274 \mathrm{tha}^{-1}$ ) and 0.78 (RMSE: $0.416 \mathrm{tha}^{-1}$ ), respectively, while the $\mathrm{SH}_{\mathrm{p} 90}$ performed best for $\mathrm{G} 2$ with an $R^{2}$ of 0.66 (RMSE: $0.287 \mathrm{tha}^{-1}$ ). The performance of the UAV-based $\mathrm{VI}_{\mathrm{RGB}}$ depended on the growth. NGRDI and VARI showed a moderate 
Table 8 Statistics of cross-validation results for bivariate linear regression of DBM yield against each predictor variable per growth. $R^{2} \mathrm{CV}$, Cross-validation coefficient of determination; $\mathrm{RMSE}_{\mathrm{CV}}$, cross-validation root mean squared error; $n$, number of samples.

\begin{tabular}{|c|c|c|c|c|c|c|c|}
\hline & & \multicolumn{2}{|r|}{ Growth 1} & \multicolumn{2}{|r|}{ Growth 2} & \multicolumn{2}{|r|}{ Growth 3} \\
\hline \multicolumn{2}{|c|}{ Estimator } & $R_{\mathrm{CV}}^{2}$ & $\mathrm{RMSE}_{\mathrm{CV}}\left(\mathrm{tha}^{-1}\right)$ & $R^{2} \mathrm{CV}$ & $\mathrm{RMSE}_{\mathrm{CV}}\left(\mathrm{tha}^{-1}\right)$ & $R^{2} \mathrm{CV}$ & $\operatorname{RMSE}_{\mathrm{CV}}\left(\mathrm{tha}^{-1}\right)$ \\
\hline & RPM & 0.87 & 0.274 & 0.58 & 0.320 & 0.78 & 0.416 \\
\hline \multirow[t]{9}{*}{ UAV } & $\mathrm{SH}_{\text {mean }}$ & 0.61 & 0.475 & 0.62 & 0.305 & 0.53 & 0.612 \\
\hline & $\mathrm{SH}_{\mathrm{p} 90}$ & 0.73 & 0.394 & 0.66 & 0.287 & 0.57 & 0.586 \\
\hline & RGBVI & 0.06 & 0.740 & 0.06 & 0.513 & 0.32 & 0.739 \\
\hline & NGRDI & 0.54 & 0.518 & 0.02 & 0.490 & 0.11 & 0.927 \\
\hline & VARI & 0.58 & 0.494 & 0.00 & 0.502 & 0.09 & 0.924 \\
\hline & ExGI & 0.24 & 0.664 & 0.01 & 0.508 & 0.55 & 0.601 \\
\hline & GrassI & 0.61 & 0.475 & 0.61 & 0.306 & 0.54 & 0.610 \\
\hline & $\mathrm{ExGl}+\mathrm{SH}_{\mathrm{p} 90}$ & 0.73 & 0.394 & 0.66 & 0.287 & 0.58 & 0.582 \\
\hline & $n$ & \multicolumn{2}{|r|}{43} & \multicolumn{2}{|r|}{42} & \multicolumn{2}{|r|}{45} \\
\hline \multirow[t]{10}{*}{ ASD } & NDVI & 0.83 & 0.360 & 0.55 & 0.295 & 0.32 & 0.767 \\
\hline & OSAVI & 0.68 & 0.490 & 0.51 & 0.306 & 0.39 & 0.723 \\
\hline & RDVI & 0.56 & 0.577 & 0.47 & 0.321 & 0.40 & 0.719 \\
\hline & REIP & 0.86 & 0.322 & 0.29 & 0.369 & 0.02 & 0.924 \\
\hline & NDREI & 0.87 & 0.316 & 0.56 & 0.291 & 0.04 & 0.915 \\
\hline & nRGBVI & 0.64 & 0.520 & 0.28 & 0.373 & 0.58 & 0.602 \\
\hline & nNGRDI & 0.76 & 0.422 & 0.37 & 0.349 & 0.57 & 0.605 \\
\hline & nVARI & 0.78 & 0.404 & 0.38 & 0.345 & 0.49 & 0.664 \\
\hline & nExGI & 0.44 & 0.648 & 0.01 & 0.459 & 0.03 & 0.923 \\
\hline & $n$ & \multicolumn{2}{|r|}{22} & \multicolumn{2}{|r|}{30} & \multicolumn{2}{|r|}{41} \\
\hline
\end{tabular}

performance with an $R^{2}$ of 0.54 and 0.58 , respectively, for G1 but showed no correlation for G2 and G3. Excluding G3-T3 (slightly lodging sward in six plots of treatments N5 and N6) led to a better performance of both indices with an $R^{2}$ of 0.42 (RMSE: $0.469 \mathrm{tha}^{-1}$ ) and 0.56 (RMSE: $0.409 \mathrm{tha}^{-1}$ ), respectively. Similarly, the $R^{2}$ of the RGBVI increased to 0.55 (RMSE: $0.416 \mathrm{tha}^{-1}$ ). However, the RGBVI showed no predictive accuracy for G1 and G2. The ExGI had little-to-no predictive accuracy for G1 and G2 but an $R^{2}$ of 0.55 (RMSE: $0.601 \mathrm{tha}^{-1}$ ) for G3. The ASD-based narrowband $\mathrm{VI}_{\mathrm{RGB}}$ performed well for DBM estimation for $\mathrm{G} 1$ and G3, except for the ExGI. However, only a weak correlation was observed for G2.

The composite indices GrassI and ExGI $+\mathrm{SH}_{\mathrm{p} 90}$ performed as expected in the range of the best-performing component (height features from CSM). The $\mathrm{VI}_{\mathrm{VNIR}}$ performed best for G1. The NDVI, REIP, and NDREI had an $R^{2}$ of $0.83,0.86$, and 0.87 , respectively, while the RDVI performed weak for G1. For G2, the $\mathrm{VI}_{\mathrm{VNIR}}$ showed moderate predictive accuracy, while the REIP only had an $R^{2}$ of 0.29 . In G3, the red-edge-based indices REIP and NDREI showed no correlation, and the NDVI, OSAVI, and RDVI showed only a weak predictive accuracy. Similar to the $\mathrm{VI}_{\mathrm{RGB}}$, the exclusion of G3-T3 increased the performance of the NDVI, REIP, and NDREI, although only a low predictive accuracy could be achieved (NDVI: $R^{2} 0.39$, RMSE $0.512 \mathrm{tha}^{-1}$; REIP: $R^{2}$ 0.24, RMSE $0.574 \mathrm{tha}^{-1}$; NDREI $R^{2} 0.26$, RMSE $0.567 \mathrm{tha}^{-1}$ ).

Table 9 presents the cross-validation results of the FBM prediction based on simple linear regression. As for the DBM prediction, $\mathrm{SH}_{\mathrm{RPM}}$ is the best predictor for $\mathrm{FBM}$ for $\mathrm{G} 1$ and $\mathrm{G} 3$ with 
Table 9 Statistics of cross-validation results for bivariate linear regression of FBM against each predictor variable per growth. $R^{2} \mathrm{CV}$, cross-validation coefficient of determination; RMSE $\mathrm{CV}_{\mathrm{CV}}$, cross-validation root mean squared error; $n$, number of samples.

\begin{tabular}{|c|c|c|c|c|c|c|c|}
\hline & & \multicolumn{2}{|r|}{ Growth 1} & \multicolumn{2}{|r|}{ Growth 2} & \multicolumn{2}{|r|}{ Growth 3} \\
\hline \multicolumn{2}{|c|}{ Estimator } & $R^{2} \mathrm{cV}$ & $\mathrm{RMSE}_{\mathrm{CV}}\left(\mathrm{tha}^{-1}\right)$ & $R^{2} \mathrm{cV}$ & $\mathrm{RMSE}_{\mathrm{CV}}\left(\mathrm{tha}^{-1}\right)$ & $R^{2} \mathrm{CV}$ & $\operatorname{RMSE}_{\mathrm{CV}}\left(\mathrm{tha}^{-1}\right)$ \\
\hline & RPM & 0.78 & 1.448 & 0.42 & 1.504 & 0.83 & 1.367 \\
\hline \multirow[t]{9}{*}{ UAV } & $\mathrm{SH}_{\text {mean }}$ & 0.71 & 1.670 & 0.60 & 1.253 & 0.38 & 2.633 \\
\hline & $\mathrm{SH}_{\mathrm{p} 90}$ & 0.79 & 1.421 & 0.65 & 1.166 & 0.43 & 2.526 \\
\hline & RGBVI & 0.12 & 2.897 & 0.55 & 2.070 & 0.31 & 2.773 \\
\hline & NGRDI & 0.68 & 1.756 & 0.06 & 1.926 & 0.00 & 3.397 \\
\hline & VARI & 0.71 & 1.648 & 0.02 & 1.977 & 0.01 & 3.418 \\
\hline & ExGI & 0.35 & 2.491 & 0.12 & 2.060 & 0.51 & 2.331 \\
\hline & GrassI & 0.71 & 1.667 & 0.59 & 1.261 & 0.38 & 2.624 \\
\hline & $\mathrm{ExGISH}_{\mathrm{p} 90}$ & 0.79 & 1.410 & 0.65 & 1.169 & 0.43 & 2.513 \\
\hline & $n$ & \multicolumn{2}{|r|}{43} & \multicolumn{2}{|r|}{42} & \multicolumn{2}{|r|}{45} \\
\hline \multirow[t]{10}{*}{ ASD } & NDVI & 0.84 & 1.393 & 0.65 & 0.868 & 0.43 & 2.576 \\
\hline & OSAVI & 0.81 & 1.515 & 0.67 & 0.842 & 0.57 & 2.252 \\
\hline & RDVI & 0.73 & 1.812 & 0.65 & 0.868 & 0.59 & 2.203 \\
\hline & REIP & 0.89 & 1.162 & 0.36 & 1.180 & 0.12 & 3.213 \\
\hline & NDREI & 0.89 & 1.172 & 0.67 & 0.842 & 0.15 & 3.161 \\
\hline & nRGBVI & 0.59 & 2.239 & 0.36 & 1.188 & 0.53 & 2.354 \\
\hline & nNGRDI & 0.73 & 1.801 & 0.47 & 1.074 & 0.61 & 2.136 \\
\hline & nVARI & 0.77 & 1.656 & 0.49 & 1.053 & 0.57 & 2.237 \\
\hline & $\mathrm{nExGI}$ & 0.34 & 2.839 & 0.00 & 1.525 & 0.00 & 3.474 \\
\hline & $n$ & \multicolumn{2}{|r|}{22} & \multicolumn{2}{|r|}{30} & \multicolumn{2}{|r|}{41} \\
\hline
\end{tabular}

an $R^{2}$ of 0.78 (RMSE: $1.448 \mathrm{tha}^{-1}$ ) and 0.83 (RMSE: $1.367 \mathrm{tha}^{-1}$ ), respectively. However, $\mathrm{SH}_{\mathrm{p} 90}$ has a slightly higher $R^{2}$ of 0.79 (RMSE: $1.421 \mathrm{tha}^{-1}$ ) for $\mathrm{G} 1$ and outperforms $\mathrm{SH}_{\mathrm{RPM}}$ for G2 with an $R^{2}$ of 0.65 (RMSE: $1.166 \mathrm{tha}^{-1}$ ).

The best-performing $\mathrm{VI}_{\mathrm{RGB}}$ for $\mathrm{G} 1$ were the NGRDI and VARI, while both indices obviously failed to estimate FBM for G2 and G3. The RGBVI showed a better predictive accuracy for FBM $\left(R^{2}: 0.55\right.$, RMSE: $\left.2.070 \mathrm{tha}^{-1}\right)$ than for DBM in G2, while the ExGI followed a similar pattern for FBM prediction as for DBM, with the best performance in G3 $\left(R^{2}: 0.51\right.$, RMSE: $2.331 \mathrm{tha}^{\mathrm{v} 1}$ ). The performance of the ASD-based narrowband $\mathrm{VI}_{\mathrm{RGB}}$ for FBM estimation was similar to that for DBM estimation. As expected, the composite indices GrassI and ExGI+SHp90 performed in the range of the best-performing single feature (height features from CSM). The $\mathrm{VI}_{\mathrm{VNIR}}$ performed best for G1. All indices had a high $R^{2}$ value above 0.70 , and both the rededge-based indices REIP and NDREI had an $R^{2}$ of 0.89. Also, for G2, the $R^{2}$ values for FBM prediction of the $\mathrm{VI}_{\mathrm{VNIR}}$ were 0.65 or slightly higher, except for the REIP, which only had an $R^{2}$ of 0.36 (RMSE: $1.180 \mathrm{tha}^{-1}$ ). For G3, the best-performing indices were the OSAVI and RDVI with an $R^{2}$ of 0.57 (RMSE: $2.252 \mathrm{tha}^{-1}$ ) and 0.59 (RMSE: $2.203 \mathrm{tha}^{-1}$ ), respectively. The lowest RMSE values were observed for the $\mathrm{VI}_{\mathrm{VNIR}}$ for G2, where all indices except the REIP had an RMSE below 0.900 tha $^{-1}$.

Observed and predicted DBM for selected features are displayed in Fig. 7. $\mathrm{SH}_{\mathrm{RPM}}$ is closest to the 1:1 line, while predictions based on NDVI and $\mathrm{SH}_{\mathrm{p} 90}$ deviate more from the regression line, especially for higher DBM values. 

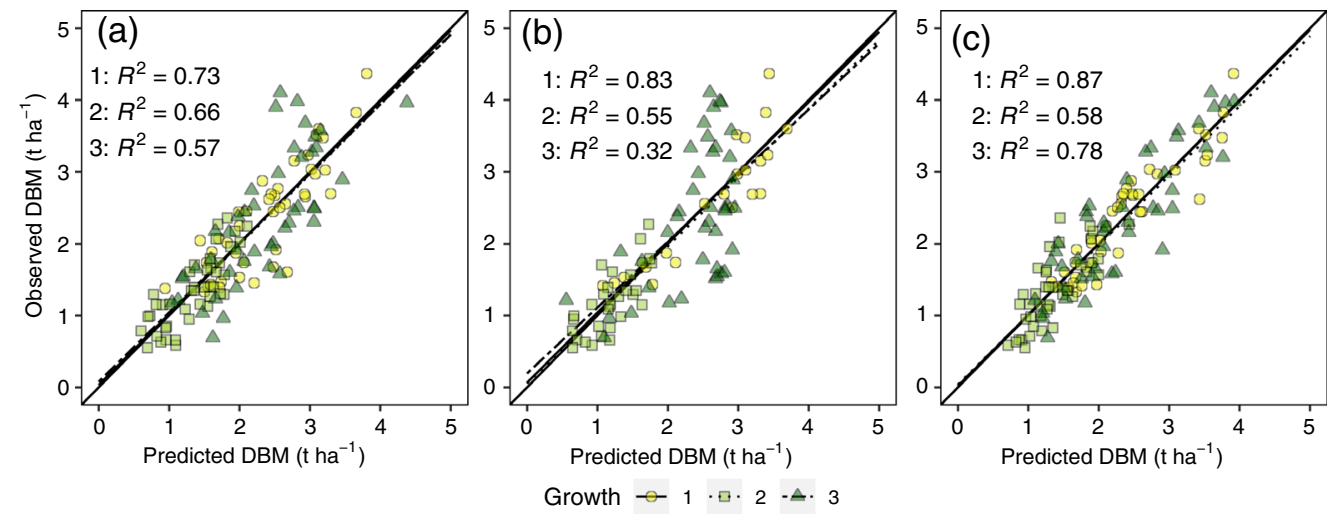

Fig. 7 Scatterplots of observed versus predicted DBM yield for (a) $\mathrm{SH}_{\mathrm{p} 90}$ as predictor variable, (b) NDVI as predictor variable, and (c) $\mathrm{SH}_{\mathrm{RPM}}$ as predictor variable. Cross-validation $R^{2}$ values are presented.

\subsection{Cross-Validation Results of Multivariate Linear Regression for Dry Biomass and Fresh Biomass}

Estimations of DBM and FBM using combined structural and spectral features by multivariate linear regression are presented in Tables 10 and 11, respectively. Since the $\mathrm{SH}_{\mathrm{p} 90}$ outperformed the $\mathrm{SH}_{\text {mean }}$ in the SLR models, the $\mathrm{SH}_{\mathrm{p} 90}$ was chosen as a structural feature for the combination with the spectral features $\left(\mathrm{VI}_{\mathrm{RGB}}\right.$ and $\left.\mathrm{VI}_{\mathrm{VNIR}}\right)$.

The combination of $\mathrm{SH}_{\mathrm{p} 90}$ and the $\mathrm{VI}_{\mathrm{RGB}}$ yielded similar results with an $R^{2}$ of 0.72 in $\mathrm{G} 1$, which is comparable to the highest best-performing single feature $\left(\mathrm{SH}_{\mathrm{p} 90}\right)$. For $\mathrm{G} 2$, the combination of $\mathrm{SH}_{\mathrm{p} 90}$ and $\mathrm{VI}_{\mathrm{RGB}}$ led to a better predictive accuracy for the NGRDI and

Table 10 Statistics of cross-validation results for multivariate linear regression of DBM against a combination of $\mathrm{SH}_{\mathrm{p} 90}$ and each VI feature. $R^{2} \mathrm{cv}$, cross-validation coefficient of determination; $\mathrm{RMSE}_{\mathrm{CV}}$, cross-validation root mean squared error; $n$, number of samples.

\begin{tabular}{|c|c|c|c|c|c|c|c|}
\hline \multicolumn{2}{|c|}{ Estimator } & \multicolumn{2}{|r|}{ Growth 1} & \multicolumn{2}{|r|}{ Growth 2} & \multicolumn{2}{|r|}{ Growth 3} \\
\hline & $\mathrm{SH}_{\mathrm{p} 90}+$ & $R^{2} \mathrm{CV}$ & $\mathrm{RMSE}_{\mathrm{CV}}\left(\mathrm{tha}^{-1}\right)$ & $R_{\mathrm{CV}}^{2}$ & $\operatorname{RMSE}_{\mathrm{CV}}\left(\mathrm{tha}^{-1}\right)$ & $R^{2} \mathrm{CV}$ & $\operatorname{RMSE}_{\mathrm{CV}}\left(\mathrm{tha}^{-1}\right)$ \\
\hline \multirow[t]{5}{*}{ UAV } & RGBVI & 0.72 & 0.404 & 0.64 & 0.296 & 0.59 & 0.570 \\
\hline & NGRDI & 0.72 & 0.402 & 0.75 & 0.248 & 0.57 & 0.585 \\
\hline & VARI & 0.72 & 0.403 & 0.73 & 0.256 & 0.60 & 0.570 \\
\hline & ExGl & 0.72 & 0.403 & 0.64 & 0.297 & 0.68 & 0.509 \\
\hline & $n$ & \multicolumn{2}{|r|}{43} & \multicolumn{2}{|r|}{42} & \multicolumn{2}{|r|}{45} \\
\hline \multirow[t]{10}{*}{ ASD } & NDVI & 0.87 & 0.307 & 0.62 & 0.272 & 0.63 & 0.562 \\
\hline & OSAVI & 0.81 & 0.379 & 0.62 & 0.272 & 0.70 & 0.507 \\
\hline & RDVI & 0.80 & 0.383 & 0.60 & 0.276 & 0.73 & 0.483 \\
\hline & REIP & 0.88 & 0.294 & 0.72 & 0.233 & 0.58 & 0.600 \\
\hline & NDREI & 0.89 & 0.288 & 0.72 & 0.232 & 0.58 & 0.599 \\
\hline & nRGBVI & 0.89 & 0.292 & 0.46 & 0.323 & 0.75 & 0.465 \\
\hline & nNGRDI & 0.89 & 0.289 & 0.49 & 0.314 & 0.73 & 0.482 \\
\hline & nVARI & 0.88 & 0.298 & 0.50 & 0.312 & 0.69 & 0.517 \\
\hline & nExGI & 0.85 & 0.330 & 0.53 & 0.300 & 0.68 & 0.523 \\
\hline & $n$ & \multicolumn{2}{|r|}{22} & \multicolumn{2}{|r|}{30} & \multicolumn{2}{|r|}{41} \\
\hline
\end{tabular}


Table 11 Statistics of cross-validation results for multivariate linear regression of FBM against a combination of $\mathrm{SH}_{\mathrm{p} 90}$ and each VI feature. $R^{2} \mathrm{cV}$, cross-validation coefficient of determination; $\mathrm{RMSE}_{\mathrm{CV}}$, cross-validation root mean squared error; $n$, number of samples.

\begin{tabular}{|c|c|c|c|c|c|c|c|}
\hline \multicolumn{2}{|c|}{ Estimator } & \multicolumn{2}{|r|}{ Growth 1} & \multicolumn{2}{|r|}{ Growth 2} & \multicolumn{2}{|r|}{ Growth 3} \\
\hline & $\mathrm{SH}_{\mathrm{p} 90}+$ & $R_{\mathrm{CV}}^{2}$ & $\operatorname{RMSE}_{\mathrm{CV}}\left(\mathrm{tha}^{-1}\right)$ & $R^{2} \mathrm{CV}$ & $\mathrm{RMSE}_{\mathrm{CV}}\left(\mathrm{tha}^{-1}\right)$ & $R_{\mathrm{CV}}^{2}$ & $\operatorname{RMSE}_{\mathrm{CV}}\left(\mathrm{tha}^{-1}\right)$ \\
\hline \multirow[t]{5}{*}{ UAV } & RGBVI & 0.78 & 1.453 & 0.64 & 1.180 & 0.47 & 2.421 \\
\hline & NGRDI & 0.81 & 1.346 & 0.78 & 0.935 & 0.41 & 2.575 \\
\hline & VARI & 0.81 & 1.335 & 0.77 & 0.954 & 0.42 & 2.546 \\
\hline & ExGI & 0.79 & 1.425 & 0.63 & 1.198 & 0.57 & 2.191 \\
\hline & $n$ & \multicolumn{2}{|r|}{43} & \multicolumn{2}{|r|}{42} & \multicolumn{2}{|r|}{45} \\
\hline \multirow[t]{10}{*}{ ASD } & NDVI & 0.92 & 1.003 & 0.67 & 0.844 & 0.59 & 2.188 \\
\hline & OSAVI & 0.90 & 1.118 & 0.71 & 0.794 & 0.72 & 1.811 \\
\hline & RDVI & 0.89 & 1.169 & 0.71 & 0.789 & 0.76 & 1.677 \\
\hline & REIP & 0.93 & 0.931 & 0.74 & 0.748 & 0.49 & 2.460 \\
\hline & NDREI & 0.93 & 0.932 & 0.78 & 0.685 & 0.49 & 2.443 \\
\hline & nRGBVI & 0.91 & 1.038 & 0.45 & 1.100 & 0.63 & 2.086 \\
\hline & nNGRDI & 0.91 & 1.011 & 0.51 & 1.038 & 0.68 & 1.945 \\
\hline & nVARI & 0.92 & 1.002 & 0.52 & 1.023 & 0.66 & 2.000 \\
\hline & nExGl & 0.88 & 1.203 & 0.44 & 1.114 & 0.50 & 2.415 \\
\hline & $n$ & \multicolumn{2}{|r|}{22} & \multicolumn{2}{|r|}{30} & \multicolumn{2}{|r|}{41} \\
\hline
\end{tabular}

VARI ( $R^{2}$ of 0.75 and 0.73 , respectively). For G3, the combination of $\mathrm{SH}_{\mathrm{p} 90}$ and ExGI showed the best result with an $R^{2}$ of 0.68 and an RMSE of $0.509 \mathrm{tha}^{-1}$. The ASD-based narrowband RGB indices performed again similar to the $\mathrm{VI}_{\mathrm{VNIR}}$ in combination with the height feature for DBM and FBM.

For the $\mathrm{VI}_{\mathrm{VNIR}}$, the results improved significantly for the combination of $\mathrm{SH}_{\mathrm{p} 90}$ with OSAVI and RDVI for G1, while the other features showed only slight improvement. For G2, the REIP and NDREI showed the best $R^{2}$ values with both 0.72, while combining $\mathrm{SH}_{\mathrm{p} 90}$ and the NDVI, OSAVI or RDVI led to $R^{2}$ values lower than the best-performing single feature $\left(\mathrm{SH}_{\mathrm{p} 90}\right)$. In G3, the combination of OSAVI and RDVI with $\mathrm{SH}_{\mathrm{p} 90}$ predicted DBM most accurately, while REIP and NDREI performed in the range of the best single feature $\left(\mathrm{SH}_{\mathrm{p} 90}\right)$. A similar pattern was observable for the multivariate estimation of FBM.

\section{Discussion}

The primary aims of this study were (1) evaluating the ability of height features and VI features derived from UAV-based image data to predict DBM and FBM in grassland and (2) comparing the performance of these features with established VIs from the VNIR spectral region and RPM reference measurements. Although Bareth and Schellberg ${ }^{6}$ found that $\mathrm{SH}_{\mathrm{RPM}}$ and the $\mathrm{SH}_{\mathrm{CSM}}$ correlated well, in this study, both features only correlate at a low-to-medium level depending on the growths. The $\mathrm{SH}_{\mathrm{CSM}}$ features tend to overestimate the manually measured $\mathrm{SH}_{\mathrm{RPM}}$, which was expected due to the compression of the sward when using the RPM. ${ }^{6}$ Furthermore, the choice of the RPM instrument might have influenced the correlation due to a different disk weight and diameter.

Recent studies using SfM-MVS to derive canopy height models for grassland have obtained reference measurements in the field with a height stick or a ruler. Dependent on the sward structure, species composition, and growing stage, Grüner et al. ${ }^{46}$ achieved $R^{2}$ values of 0.56 and 0.70 and Viljanen et al. ${ }^{7}$ report $R^{2}$ values of 0.61 to 0.93 when comparing $\mathrm{SH}_{\mathrm{CSM}}$ with manual reference measurements from height sticks. Forsmoo et al. ${ }^{47}$ achieved $R^{2}$ values of 0.64 and 0.72 
when comparing reference measurements from $\mathrm{RPMs}$ and $\mathrm{SH}_{\mathrm{CSM}}$ for a grassland field of mainly perennial ryegrass and clover in southwest England. Higher correlation between RPM reference measurements and low-cost $\mathrm{SH}_{\mathrm{CSM}}\left(R^{2}\right.$ of 0.83 to 0.91$)$ were reported by Bareth and Schellberg ${ }^{6}$ for three consecutive years in the long-term Rengen Grassland Experiment (RGE) in Germany. In contrast to manual measurements, the CSM approach captures the spatial variability of the plant height in much finer detail.

To obtain sward height, the CSM-approach described by Bendig et al ${ }^{49}$ was used. Table 2 shows that the errors of the reconstructed DSMs in $X, Y$, and $Z$ directions were within the range of up to $7.3 \mathrm{~cm}$, which clearly have an impact on calculating sward height when DSM-T $T_{0}$ is subtracted from DSM-T $\mathrm{T}_{1-n}$. The high error rates may be due to several factors such as the suboptimal placement of GCPs or the sensor geometry of the DJI P4A camera. Owing to overgrowing of the border strips between the plots, it was not possible to classify a DTM representing the ground for every sampling date. For small-scale field experiments, DTM classification or measuring ground surface points with an real time kinematic differential GPS may be more feasible. Nevertheless, the CSM approach by Bendig et al ${ }^{49}$ may be more applicable to actual field conditions since ground surface classification may not be viable for a fully covered grassland field of several hectares with varying topography. However, the CSM approach by Bendig et $\mathrm{al}^{49}$ requires that the data for the base model are acquired over the bare soil surface of the field, which is not feasible for grassland fields due to permanent vegetation coverage.

The high rodent activity in a few plots per growth led to higher uncertainties in $\mathrm{SH}_{\mathrm{CSM}}$ calculation, which, in some cases, resulted in negative sward height values and unreasonable biomass values. The decision to exclude these plots improved the biomass estimation, although these disturbances are likely to occur in the field.

Biomass prediction models based on LOO-CV results showed moderate accuracies depending on the growths when using the height features $\left(\mathrm{SH}_{\text {mean }}\right.$ and $\left.\mathrm{SH}_{\mathrm{p} 90}\right)$. Viljanen et al. ${ }^{7}$ reported correlation coefficients between 0.75 and 0.98 for biomass prediction using height features from CSM but concluded that biomass prediction accuracy was dependent on the density and growth stage of the sward. Näsi et al. ${ }^{36}$ reported correlation coefficients for grassland biomass prediction between 0.10 and 0.41 . Grüner et al. ${ }^{46}$ achieved $R^{2}$ values of 0.46 and up to 0.87 depending on the sward composition for mixed legume-grass swards and pure legumes and grass stands. Roth and $\mathrm{Streit}^{50}$ analyzed different cover crops, and the prediction accuracy for biomass improved when lodging plants were excluded from the analysis. Our findings are, thus, comparable to other studies. Since G2 was affected by drought (see Fig. 3), low biomass, low tiller density, and low sward heights in G2 led to a weak correlation when all growths were combined in a single regression analysis (see Fig. 8).

Similar results were also observed by Grüner et al. ${ }^{46}$ when pure grass stands from the second growth in 2017 were excluded. These findings indicate that challenges remain when using SfMMVS reconstruction to determine a global model for biomass estimation in pure grass swards.

The varying accuracy especially of the $\mathrm{VI}_{\mathrm{RGB}}$ from the orthomosaics as biomass predictors might be explained by several factors such as the varying soil color due to rainfall events or drought, bent stalks or flowers. Owing to vigorous growth in plots of treatments N5 and N6 in G3-T3, stalks tended to bend over, and as a result, a higher proportion of the spectral signature of the stalks was captured instead of the desired nadir view of the canopy (see Fig. 2). In this study, the correlation of the UAV-based $\mathrm{VI}_{\mathrm{RGB}}$ by growth and treatment did not yield more robust results than the analysis of the features excluding the treatment effects. Furthermore, no clear pattern between treatments and VIs is recognizable in the sensitivity analysis (see Tables 14-16). For clarification, an extended sensitivity analysis of all single features can be found in the Appendix.

Dependent on the sampling date, the illumination conditions were stable but either sunny or overcast, which probably contributed significantly to the UAV-based $\mathrm{VI}_{\mathrm{RGB}}$ values. This observation was also shown by Rasmussen et al. $^{71}$ for wheat. Furthermore, the effect of rainfall shortly before image acquisition probably influenced the $\mathrm{VI}_{\mathrm{RGB}}$ values due to changing soil color (see Fig. 1) The study by Viljanen et al. ${ }^{7}$ achieved correlation coefficients of 0.70 to 0.85 for the correlation of biomass and RGBVI, NGRDI, and ExGI. However, for the random forest classifier, the $\mathrm{VI}_{\mathrm{RGB}}$ was not among the most important features in estimating grass biomass.

The choice of multiple linear regression (one VI feature + one height feature) was motivated by the search for a robust and simple model that can be applied to different growths per season. 

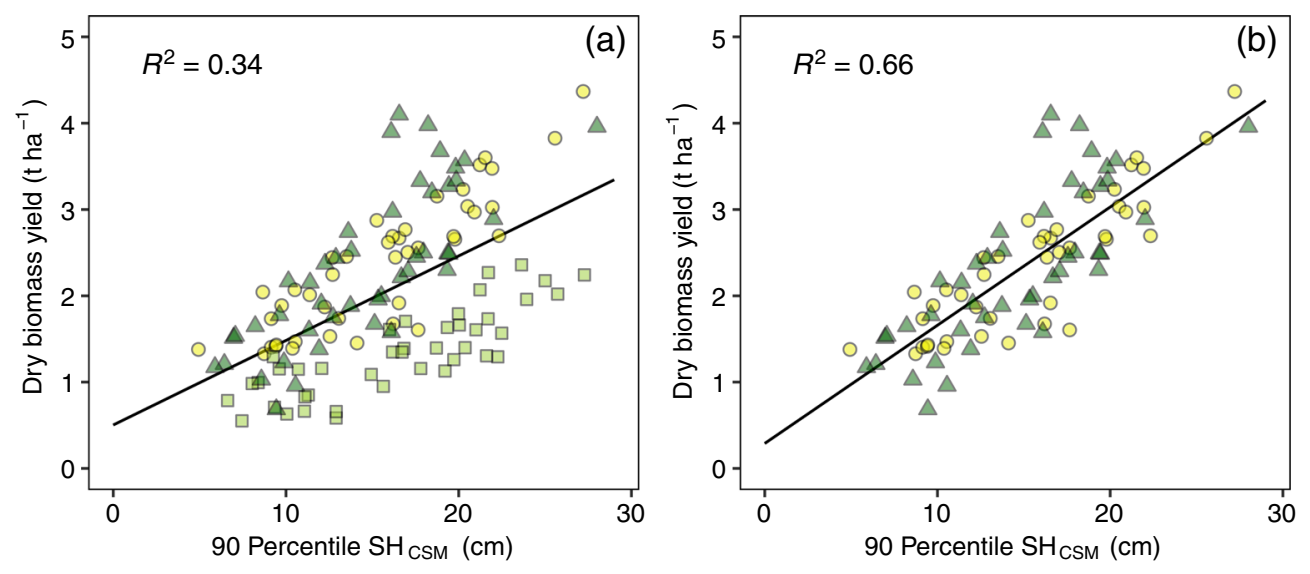

Growth $\bigcirc \quad 1 \quad \square \quad 2 \quad \Delta \quad 3$

Fig. 8 Relationship between (a) 90th percentile CSM-based sward height and DBM yield for all growths in 2017 and (b) only for growths 1 and 2.

Initial tests on different interaction terms for the MLR (such as VI feature $\times$ height feature) did not yield more robust results.

The performance of the composite VIs GrassI and $\mathrm{ExGI}+\mathrm{SH}_{\mathrm{p} 90}$ did not yield significantly better results than the multivariate regression of the respective $\mathrm{VI}_{\mathrm{RGB}}$ and height features, as they rely on the quality of both features. Owing to the different viewing geometry and technique of the ASD-based VIs, these features are not directly comparable to the results of the UAV-based $\mathrm{VI}_{\mathrm{RGB}}$. As expected, VIs from a well-calibrated instrument, and including the NIR spectral region, performed better and more consistently over all growths than the UAV-based $\mathrm{VI}_{\mathrm{RGB}} \cdot{ }^{24,38}$ However, all ASD-based VIs had a decreasing accuracy from G1 to G3 and were affected by slightly lodging sward in six plots with higher $\mathrm{N}$-treatments, as mentioned already. The ASD-based narrowband $\mathrm{VI}_{\mathrm{RGB}}$ validates the respective VIs as viable for biomass prediction in grassland and demonstrate the challenges associated with uncalibrated sensors such as the camera used in this study.

The heterogeneous sward structure with high spatiotemporal variability compared to crops led to varying performance for biomass estimation depending on the growths and choice of predictor variable. It is therefore essential to study this topic further and to evaluate different swards under varying conditions and sites and over multiple years. A promising approach is the application of high-resolution multispectral imaging sensors, such as the MicaSense RedEdge camera (Micasense Inc., Seattle), which can readily be employed on a UAV. Furthermore, comparing simple regression techniques with more sophisticated algorithms such as random forest should be explored for larger datasets of grassland biomass and UAV-based structural and spectral features.

\section{Conclusions}

Estimating biomass in high spatial and temporal resolution is a key component in precision agriculture applications and ecosystem monitoring. In this study, SfM-MVS-derived features of sward height and VIs from UAV-based images were assessed as predictors of grassland above-ground biomass and compared to established narrowband VIs from spectroradiometer measurements. The application of UAV-based imaging sensors serves as a fast and nondestructive method for data acquisition with high spatial and temporal resolution.

This study has shown that, especially for the first growth, which is considered the most important from an agronomical point of view, grassland biomass estimation by SfM-MVS-derived sward height from UAV-based images is feasible and provides an alternative means to manual measurement techniques such as RPMs or clipping. However, the results are influenced by various factors such as growing stage, sward composition, and biotic and abiotic factors, which need to be further investigated. Further research should be focused on integrating structural and spectral features for grassland biomass estimation and on generalizing models to different sites and years. 


\section{Appendix}

The appendix contains Tables 12-19 for sensitivity analysis (Pearson's correlation coefficient, PCC) of the features (vegetation indices and canopy height) tested in this study for estimation of dry biomass yield (DBM).

Table 12 PCCs for DBM and UAV-based VIs by growth (G). ExGI, ExcessGreen Index; NGRDI, Normalized Green Red Difference Index; RGBVI, Red-Green-Blue Vegetation Index; VARI, Visible Atmospherically Resistant Index.

\begin{tabular}{|c|c|c|c|c|}
\hline G & ExGI & NGRDI & RGBVI & VARI \\
\hline 1 & $0.54^{*}$ & $0.76^{\star}$ & $0.34^{\star \star \star}$ & $0.79^{*}$ \\
\hline 2 & $0.20^{\star \star \star \star \star}$ & $0.29^{\star \star \star \star}$ & $0.14^{\star \star \star \star \star}$ & $0.20^{\star \star \star \star \star}$ \\
\hline 3 & $0.76^{*}$ & $0.10^{\star \star \star \star \star \star}$ & $0.60^{*}$ & $0.09^{\star \star \star \star \star \star}$ \\
\hline
\end{tabular}

${ }^{\star} P \leq 0.001$.

${ }^{\star *} P \leq 0.01$.

${ }^{* * *} P \leq 0.05$

${ }^{* \star \star \star} P \leq 0.1$

$* \star * \star * P \leq 0.5$.

${ }^{\star \star \star \star \star \star \star} P \leq 0.99$

Table 13 PCCs for DBM and narrowband ASD-based VIs by growth (G). NDREI, Normalized Difference Red-Edge Index; NDVI, Normalized Difference Vegetation Index; OSAVI, Optimized Soil Adjusted Vegetation Index; RDVI, Renormalized Difference Vegetation Index; REIP, Red Edge Inflection Point; nExGI, ExcessGreen Index; nNGRDI, Normalized Green Red Difference Index; nRGBVI, Red-Green-Blue Vegetation Index; and nVARI, Visible Atmospherically Resistant Index.

\begin{tabular}{|c|c|c|c|c|c|c|c|c|c|}
\hline G & NDREI & NDVI & OSAVI & RDVI & REIP & nExGI & nNGRDI & nRGBVI & nVARI \\
\hline 1 & $0.94^{*}$ & $0.93^{*}$ & $0.86^{\star}$ & $0.79^{*}$ & $0.94^{*}$ & $-0.72^{\star}$ & $0.90^{*}$ & $0.84^{*}$ & $0.91^{*}$ \\
\hline 2 & $0.78^{*}$ & $0.78^{*}$ & $0.76^{\star}$ & $0.73^{*}$ & $0.62^{*}$ & $0.20^{\star \star \star \star \star *}$ & $0.67^{\star}$ & $0.61^{*}$ & $0.68^{\star}$ \\
\hline 3 & $0.33^{\star \star \star}$ & $0.61^{*}$ & $0.67^{*}$ & $0.67^{\star}$ & $0.30^{\star \star \star *}$ & $0.32^{\star \star \star}$ & $0.78^{*}$ & $0.78^{*}$ & $0.73^{*}$ \\
\hline
\end{tabular}

${ }^{\star} P \leq 0.001$

${ }^{* *} P \leq 0.01$.

${ }^{* * *} P \leq 0.05$.

${ }^{\star \star \star *} P \leq 0.1$.

${ }^{* * * * *} P \leq 0.5$

${ }^{\star \star \star \star \star *} P \leq 0.99$.

Table 14 PCCs for DBM and UAV-based VIs and height features by growth (G) and treatment (N: kg N / ha). ExGI, ExcessGreen Index; NGRDI, Normalized Green Red Difference Index; RGBVI, Red-Green-Blue Vegetation Index; VARI, Visible Atmospherically Resistant Index; $\mathrm{SH}_{\text {mean }}$, mean sward height from CSMs; $\mathrm{SH}_{\mathrm{p} 90}$, 90th percentile sward height from CSM.

\begin{tabular}{|c|c|c|c|c|c|c|c|}
\hline $\mathrm{G}$ & $\mathrm{N}$ & ExGI & NGRDI & RGBVI & VARI & $\mathrm{SH}_{\text {mean }}$ & $\mathrm{SH}_{\mathrm{p} 90}$ \\
\hline \multirow[t]{6}{*}{1} & 0 & $0.47^{\star \star \star \star \star}$ & $0.68^{\star \star \star \star}$ & $0.31^{\star \star \star \star \star *}$ & $0.71^{\star \star \star}$ & $0.90^{* *}$ & $0.90^{* *}$ \\
\hline & 100 & $0.72^{\star \star \star \star \star}$ & $0.71^{\star \star \star \star \star}$ & $0.74^{\star \star \star \star}$ & $0.70^{\star \star \star \star *}$ & $-0.02^{\star \star \star \star \star \star \star}$ & $0.19^{\star \star \star \star \star \star *}$ \\
\hline & 200 & $0.20^{\star \star \star \star \star \star \star ~}$ & $0.47^{\star \star \star \star \star}$ & $0.07^{\star \star \star \star \star \star \star ~}$ & $0.55^{\star \star \star \star \star}$ & $0.69^{\star \star \star}$ & $0.85^{\star *}$ \\
\hline & 300 & $0.78^{\star \star \star}$ & $0.78^{\star \star \star}$ & $0.73^{\star \star \star}$ & $0.75^{\star \star \star}$ & $0.80^{\star \star \star}$ & $0.84^{* *}$ \\
\hline & 400 & $0.63^{\star \star \star \star \star}$ & $0.77^{\star \star \star}$ & $0.59^{\star \star \star \star \star}$ & $0.80^{\star \star \star}$ & $0.91^{\star *}$ & $0.95^{\star}$ \\
\hline & 500 & $0.01^{\star \star * \star \star *}$ & $0.24^{\star \star \star \star \star \star}$ & $-0.06^{\star \star \star \star \star \star *}$ & $0.33^{\star \star \star \star \star \star *}$ & $0.71^{\star \star \star \star \star}$ & $0.81^{\star \star \star \star}$ \\
\hline
\end{tabular}


Table 14 (Continued).

\begin{tabular}{|c|c|c|c|c|c|c|c|}
\hline $\mathrm{G}$ & $\mathrm{N}$ & ExGI & NGRDI & RGBVI & VARI & $\mathrm{SH}_{\text {mean }}$ & $\mathrm{SH}_{\mathrm{p} 90}$ \\
\hline \multirow[t]{6}{*}{2} & 0 & $0.51^{\star \star \star \star \star}$ & $0.10^{\star \star \star \star \star \star \star ~}$ & $0.42^{\star \star \star \star \star}$ & $0.05^{\star \star \star \star \star \star *}$ & $0.78^{\star \star \star}$ & $0.78^{\star \star \star}$ \\
\hline & 100 & $-0.02^{\star \star \star \star \star * \star}$ & $0.45^{\star \star \star \star \star}$ & $-0.09^{\star * \star * \star *}$ & $0.44^{\star \star \star \star *}$ & $0.81^{* * *}$ & $0.85^{\star \star *}$ \\
\hline & 200 & $0.09^{\star \star \star \star \star \star *}$ & $0.04^{\star \star \star \star \star \star *}$ & $0.08^{\star \star \star \star \star \star *}$ & $-0.00^{\star \star \star \star \star * *}$ & $0.86^{\star *}$ & $0.85^{\star *}$ \\
\hline & 300 & $-0.06^{\star \star \star \star \star \star \star}$ & $0.19^{\star \star \star \star \star \star \star}$ & $-0.10^{\star \star \star \star \star \star \star}$ & $0.17^{\star * \star * \star *}$ & $0.76^{\star \star \star}$ & $0.81^{\star \star \star}$ \\
\hline & 400 & $0.36^{\star \star \star \star \star}$ & $-0.54^{\star \star \star \star \star}$ & $0.35^{\star \star \star \star \star}$ & $-0.59^{\star \star \star \star \star \star}$ & $0.93^{\star \star}$ & $0.92^{\star \star}$ \\
\hline & 500 & $-0.38^{\star \star \star \star \star * *}$ & $-0.35^{\star \star \star \star \star \star}$ & $-0.37^{\star \star \star \star \star \star}$ & $-0.26^{\star \star \star \star \star \star}$ & $0.90^{\star * *}$ & $0.91^{* * *}$ \\
\hline \multirow[t]{6}{*}{3} & 0 & $0.90^{\star \star}$ & $0.26^{\star \star \star \star \star \star}$ & $0.89^{\star \star}$ & $0.17^{\star \star \star \star \star \star}$ & $0.49^{\star \star \star \star \star}$ & $0.55^{\star \star \star \star \star}$ \\
\hline & 100 & $0.95^{\star}$ & $-0.14^{\star \star \star \star \star \star}$ & $0.97^{\star}$ & $-0.22^{\star \star \star \star \star \star \star}$ & $0.79^{\star \star \star}$ & $0.80^{\star \star \star}$ \\
\hline & 200 & $0.95^{\star}$ & $-0.36^{\star * \star \star *}$ & $0.87^{\star \star}$ & $-0.24^{\star \star \star \star \star * *}$ & $0.92^{\star *}$ & $0.95^{\star}$ \\
\hline & 300 & $0.74^{\star \star \star}$ & $-0.53^{\star \star \star \star \star}$ & $0.12^{\star \star \star \star \star \star}$ & $-0.25^{\star \star \star \star \star \star \star}$ & $0.62^{\star \star \star \star}$ & $0.65^{\star \star \star \star}$ \\
\hline & 400 & $0.48^{\star \star \star \star \star}$ & $-0.50^{\star \star \star \star \star}$ & $-0.12^{\star \star \star \star \star \star \star}$ & $-0.18^{\star \star \star \star \star \star \star}$ & $0.79^{\star \star \star}$ & $0.76^{\star \star \star}$ \\
\hline & 500 & $0.70^{\star \star \star \star \star}$ & $-0.32^{\star \star \star \star \star \star \star ~}$ & $0.32^{\star \star \star \star \star \star *}$ & $-0.22^{\star \star \star \star \star \star}$ & $0.77^{\star \star \star \star}$ & $0.79^{\star \star \star \star}$ \\
\hline
\end{tabular}

${ }^{\star} P \leq 0.001$

${ }^{\star \star} P \leq 0.01$.

${ }^{* * *} P \leq 0.05$

${ }^{* * * *} P \leq 0.1$.

$\star * \star \star \star x \leq 0.5$.

${ }^{\star * * \star * *} P \leq 0.99$

Table 15 PCCs for DBM and narrowband ASD-based RGB VIs by growth (G) and treatment (N: kg N / ha). nExGI, ExcessGreen Index; nNGRDI, Normalized Green Red Difference Index; nRGBVI, Red-Green-Blue Vegetation Index; nVARI, Visible Atmospherically Resistant Index.

\begin{tabular}{|c|c|c|c|c|c|}
\hline G & $\mathrm{N}$ & nExGI & nNGRDI & nRGBVI & nVARI \\
\hline \multirow[t]{6}{*}{1} & 0 & $0.64^{\star \star \star \star \star *}$ & $0.41^{* \star \star * \star *}$ & $0.16^{\star \star \star \star \star \star *}$ & $0.52^{\star \star \star \star \star *}$ \\
\hline & 100 & $0.27^{\star \star \star \star \star \star}$ & $0.97^{\star * *}$ & $0.97^{\star \star \star}$ & $0.96^{\star \star \star}$ \\
\hline & 200 & $-0.16^{\star \star \star \star \star \star}$ & $0.78^{\star \star \star \star \star}$ & $0.70^{\star \star \star \star \star}$ & $0.82^{\star \star \star \star \star}$ \\
\hline & 300 & $-0.93^{\star \star \star \star \star}$ & $0.99^{* * \star * *}$ & $0.98^{\star * \star * *}$ & $0.78^{\star * * * *}$ \\
\hline & 400 & $-0.48^{\star \star \star \star \star \star *}$ & $0.49^{\star \star \star \star \star \star *}$ & $0.31^{\star \star \star \star \star \star *}$ & $0.61^{\star \star \star \star \star}$ \\
\hline & 500 & $-0.92^{\star \star \star \star \star}$ & $-0.48^{\star \star \star \star \star \star}$ & $-0.40^{\star \star \star \star \star \star *}$ & $-0.61^{\star \star \star \star \star \star \star}$ \\
\hline \multirow[t]{6}{*}{2} & 0 & $0.57^{\star \star \star \star *}$ & $0.68^{* * \star * *}$ & $0.73^{* \star \star \star *}$ & $0.67^{\star \star \star \star *}$ \\
\hline & 100 & $0.41^{\star * \star * * *}$ & $0.59^{\star \star \star \star *}$ & $0.56^{\star \star \star \star \star}$ & $0.59^{\star \star \star \star \star}$ \\
\hline & 200 & $0.29^{\star \star \star \star \star \star}$ & $0.63^{\star \star \star \star \star *}$ & $0.62^{\star \star \star \star \star}$ & $0.63^{\star \star \star \star \star}$ \\
\hline & 300 & $0.57^{\star \star \star \star \star}$ & $0.64^{\star \star \star \star \star}$ & $0.64^{\star \star \star \star \star}$ & $0.65^{\star \star \star \star \star}$ \\
\hline & 400 & $0.41^{\star \star \star \star *}$ & $0.74^{\star \star \star \star \star}$ & $0.73^{\star \star \star \star \star}$ & $0.74^{\star \star \star \star \star}$ \\
\hline & 500 & $-0.42^{\star \star \star \star \star \star \star}$ & $-0.23^{\star \star \star \star \star \star}$ & $-0.17^{\star \star \star \star \star \star}$ & $-0.26^{\star \star \star \star \star \star *}$ \\
\hline
\end{tabular}


Table 15 (Continued).

\begin{tabular}{|c|c|c|c|c|c|}
\hline $\mathrm{G}$ & $\mathrm{N}$ & nExGl & nNGRDI & nRGBVI & nVARI \\
\hline \multirow[t]{6}{*}{3} & 0 & $0.24^{\star \star \star \star \star \star *}$ & $0.82^{\star * *}$ & $0.83^{\star \star \star}$ & $0.81^{\star \star \star}$ \\
\hline & 100 & $0.80^{\star * *}$ & $0.96^{*}$ & $0.98^{*}$ & $0.95^{\star *}$ \\
\hline & 200 & $0.37^{\star \star \star \star \star}$ & $0.70^{\star \star \star \star}$ & $0.76^{\star \star \star}$ & $0.57^{\star \star \star \star \star}$ \\
\hline & 300 & $0.73^{\star \star \star \star}$ & $0.81^{\star \star \star}$ & $0.89^{\star *}$ & $0.70^{\star \star \star *}$ \\
\hline & 400 & $0.58^{\star \star \star \star \star}$ & $0.80^{\star \star \star}$ & $0.85^{\star \star \star}$ & $0.50^{\star \star \star \star \star}$ \\
\hline & 500 & $0.83^{\star \star \star}$ & $0.83^{\star * *}$ & $0.85^{\star \star \star}$ & $0.79^{\star \star \star \star}$ \\
\hline
\end{tabular}

${ }^{*} P \leq 0.001$.

${ }^{\star \star} P \leq 0.01$.

${ }^{* * \star} P \leq 0.05$

${ }^{* * * *} P \leq 0.1$

${ }^{* \star \star * \star *} P \leq 0.5$.

${ }^{\star \star \star \star \star \star *} P \leq 0.99$

Table 16 PCCs for DBM and ASD-based VNIR VIs by growth (G) and treatment (N: kg N / ha). NDREI, Normalized Difference Red-Edge Index; NDVI, Normalized Difference Vegetation Index; OSAVI, Optimized Soil Adjusted Vegetation Index; RDVI, Renormalized Difference Vegetation Index; REIP, Red Edge Inflection Point.

\begin{tabular}{|c|c|c|c|c|c|c|}
\hline $\mathrm{G}$ & $\mathrm{N}$ & NDREI & NDVI & OSAVI & RDVI & REIP \\
\hline \multirow[t]{6}{*}{1} & 0 & $0.45^{\star \star \star \star \star \star}$ & $0.43^{\star \star \star \star \star \star}$ & $0.57^{\star \star \star \star \star}$ & $0.54^{\star \star \star \star \star}$ & $0.34^{\star \star \star \star * \star *}$ \\
\hline & 100 & $0.71^{\star \star * \star *}$ & $0.86^{\star \star \star \star \star}$ & $0.33^{\star \star \star \star \star \star}$ & $0.07^{\star \star \star \star \star \star *}$ & $0.49^{\star \star \star \star \star \star}$ \\
\hline & 200 & $0.77^{\star \star \star \star \star}$ & $0.73^{\star \star \star \star \star}$ & $0.37^{\star \star \star \star \star \star}$ & $0.15^{\star \star \star \star \star \star}$ & $0.77^{\star \star \star \star \star}$ \\
\hline & 300 & $0.90^{\star \star \star \star \star}$ & $1.00^{\star \star \star \star}$ & $-0.54^{\star \star \star \star \star \star ~}$ & $-0.73^{\star \star \star \star \star}$ & $0.80^{\star \star \star \star \star}$ \\
\hline & 400 & $0.84^{\star \star \star \star \star}$ & $0.66^{\star \star \star \star *}$ & $0.63^{\star \star \star \star \star}$ & $0.24^{\star \star \star \star \star \star *}$ & $0.91^{\star \star \star \star}$ \\
\hline & 500 & $0.87^{\star \star \star \star \star}$ & $0.91^{* \star \star \star *}$ & $-0.97^{\star \star \star \star \star}$ & $-0.99^{\star \star \star \star}$ & $0.91^{\star \star * \star *}$ \\
\hline \multirow[t]{6}{*}{2} & 0 & $0.76^{\star \star \star \star}$ & $0.75^{\star \star \star \star}$ & $0.73^{\star \star \star \star}$ & $0.71^{\star \star \star \star \star *}$ & $-0.01^{\star \star \star \star \star \star *}$ \\
\hline & 100 & $0.75^{\star \star \star \star \star}$ & $0.59^{\star \star \star \star \star}$ & $0.52^{\star \star \star \star \star}$ & $0.47^{\star \star \star \star \star \star}$ & $0.41^{\star \star \star \star \star \star \star ~}$ \\
\hline & 200 & $0.81^{\star \star \star \star}$ & $0.67^{\star \star \star \star \star}$ & $0.60^{\star \star \star \star \star}$ & $0.55^{\star \star \star \star \star}$ & $0.68^{\star \star \star \star \star}$ \\
\hline & 300 & $0.40^{\star \star \star \star \star \star}$ & $0.58^{\star \star \star \star *}$ & $0.65^{\star \star \star \star \star}$ & $0.69^{\star \star \star \star \star}$ & $0.12^{\star \star \star \star \star \star}$ \\
\hline & 400 & $0.92^{\star \star \star}$ & $0.80^{\star \star \star \star \star \star *}$ & $0.70^{\star \star \star \star \star *}$ & $0.63^{\star \star \star * \star}$ & $0.91^{\star * *}$ \\
\hline & 500 & $-0.65^{\star \star \star \star \star}$ & $-0.30^{\star \star \star \star \star \star * ~}$ & $-0.59^{\star \star \star \star \star}$ & $-0.77^{\star \star \star \star \star}$ & $-0.53^{\star \star \star \star \star}$ \\
\hline \multirow[t]{6}{*}{3} & 0 & $0.81^{* * *}$ & $0.87^{\star \star *}$ & $0.63^{\star \star \star \star *}$ & $0.50^{\star \star \star \star *}$ & $0.65^{\star \star \star \star \star *}$ \\
\hline & 100 & $-0.02^{* \star \star \star \star *}$ & $0.86^{\star \star *}$ & $0.91^{\star *}$ & $0.88^{\star *}$ & $-0.28^{\star \star * \star * *}$ \\
\hline & 200 & $-0.07^{\star \star \star \star \star \star \star}$ & $0.58^{\star \star \star \star \star}$ & $0.43^{\star \star \star \star *}$ & $0.39^{\star \star \star \star \star}$ & $-0.17^{\star \star \star \star \star \star *}$ \\
\hline & 300 & $-0.38^{\star \star \star \star *}$ & $0.40^{\star \star \star \star \star}$ & $0.79^{\star \star *}$ & $0.78^{\star \star *}$ & $-0.40^{\star \star \star \star \star}$ \\
\hline & 400 & $-0.54^{\star \star \star \star \star}$ & $-0.18^{\star \star \star \star \star *}$ & $-0.07^{\star * \star \star \star *}$ & $-0.01^{\star \star \star \star \star *}$ & $-0.47^{\star \star \star \star \star}$ \\
\hline & 500 & $0.34^{\star \star \star \star \star \star}$ & $0.67^{\star \star \star \star \star}$ & $0.88^{\star \star \star}$ & $0.91^{\star \star *}$ & $0.34^{\star \star \star \star \star \star}$ \\
\hline
\end{tabular}

$$
\begin{aligned}
& { }^{*} P \leq 0.001 \text {. } \\
& { }^{* \star} P \leq 0.01 \text {. } \\
& { }^{* \star \star} P \leq 0.05 \\
& { }^{* * \star *} P \leq 0.1 \text {. } \\
& { }^{\star \star \star * \star \star} P \leq 0.5 \\
& { }^{\star \star \star \star \star \star \star} P \leq 0.99 \text {. }
\end{aligned}
$$


Table 17 PCCs for DBM and UAV-based VIs and height features by growth (G) and sampling date (T). ExGI, ExcessGreen Index; NGRDI, Normalized Green Red Difference Index; RGBVI, Red-Green-Blue Vegetation Index; VARI, Visible Atmospherically Resistant Index; $\mathrm{SH}_{\text {mean }}$, mean sward height from CSMs; $\mathrm{SH}_{\mathrm{pg0}}$, 90th percentile sward height from CSM.

\begin{tabular}{|c|c|c|c|c|c|c|c|}
\hline G & $\mathrm{T}$ & ExGI & NGRDI & RGBVI & VARI & $\mathrm{SH}_{\text {mean }}$ & $\mathrm{SH}_{\mathrm{p} 90}$ \\
\hline \multirow[t]{3}{*}{1} & $17-04-26$ & $0.50^{\star \star \star \star}$ & $0.80^{*}$ & $0.34^{\star \star \star *}$ & $0.84^{*}$ & $0.76^{*}$ & $0.79^{*}$ \\
\hline & $17-05-03$ & $0.83^{*}$ & $0.88^{*}$ & $0.52^{\star \star \star}$ & $0.86^{*}$ & $0.85^{*}$ & $0.88^{*}$ \\
\hline & $17-05-10$ & $0.81^{* *}$ & $0.97^{*}$ & $0.35^{\star \star \star \star}$ & $0.96^{*}$ & $0.99^{*}$ & $0.99^{*}$ \\
\hline \multirow[t]{3}{*}{2} & $17-06-07$ & $0.76^{*}$ & $0.82^{*}$ & $0.68^{\star *}$ & $0.82^{*}$ & $0.70^{\star \star}$ & $0.73^{\star \star}$ \\
\hline & $17-06-20$ & $0.03^{\star \star \star \star \star \star}$ & $0.53^{\star \star \star}$ & $0.01^{\star \star \star \star \star \star \star}$ & $0.56^{\star \star \star}$ & $0.68^{\star \star}$ & $0.70^{\star \star}$ \\
\hline & $17-06-28$ & $-0.23^{\star \star \star \star}$ & $0.14^{\star \star \star \star \star \star}$ & $-0.25^{\star \star \star \star}$ & $0.30^{\star \star \star *}$ & $0.75^{\star \star}$ & $0.85^{\star}$ \\
\hline \multirow[t]{3}{*}{3} & 17-08-02 & $0.76^{\star \star}$ & $0.75^{\star *}$ & $0.77^{*}$ & $0.69^{\star \star}$ & $0.17^{\star \star \star \star \star \star *}$ & $0.25^{\star \star \star \star}$ \\
\hline & 17-08-09 & $0.65^{\star *}$ & $0.71^{\star *}$ & $0.72^{\star *}$ & $0.68^{\star \star}$ & $0.67^{\star \star}$ & $0.67^{\star *}$ \\
\hline & $17-08-22$ & $-0.06^{\star \star \star \star \star \star *}$ & $0.68^{\star *}$ & $-0.52^{\star \star \star \star}$ & $0.71^{\star \star}$ & $0.65^{\star \star *}$ & $0.67^{\star *}$ \\
\hline
\end{tabular}

${ }^{*} P \leq 0.001$.

${ }^{* *} P \leq 0.01$.

${ }^{\star * \star} P \leq 0.05$

${ }^{* \star * \star} P \leq 0.1$

${ }^{* * * * \star} P \leq 0.5$.

${ }^{* * * * \star} P \leq 0.99$

Table 18 PCCs for DBM and narrowband ASD-based RGB VIs by growth $(G)$ and sampling date (T). nExGI, ExcessGreen Index; nNGRDI, Normalized Green Red Difference Index; nRGBVI, Red-Green-Blue Vegetation Index; nVARI, Visible Atmospherically Resistant Index.

\begin{tabular}{|c|c|c|c|c|c|}
\hline $\mathrm{G}$ & $\mathrm{T}$ & nExGI & nNGRDI & nRGBVI & nVARI \\
\hline \multirow[t]{2}{*}{1} & $17-05-03$ & $-0.69^{\star \star *}$ & $0.88^{*}$ & $0.83^{*}$ & $0.89^{*}$ \\
\hline & $17-05-10$ & $-0.73^{\star \star \star}$ & $0.93^{*}$ & $0.86^{* *}$ & $0.94^{*}$ \\
\hline \multirow[t]{2}{*}{2} & $17-06-07$ & $-0.07^{\star \star \star \star \star \star *}$ & $0.78^{*}$ & $0.72^{\star \star}$ & $0.78^{*}$ \\
\hline & $17-06-20$ & $-0.59^{\star \star \star}$ & $0.22^{\star \star \star \star \star \star *}$ & $0.07^{\star \star \star \star \star \star}$ & $0.23^{\star \star \star \star \star \star \star}$ \\
\hline \multirow[t]{3}{*}{3} & $17-08-02$ & $-0.42^{\star \star \star \star \star \star \star}$ & $0.80^{*}$ & $0.71^{\star \star}$ & $0.82^{\star}$ \\
\hline & $17-08-09$ & $-0.50^{\star \star \star \star}$ & $0.71^{\star \star \star}$ & $0.52^{\star \star \star \star}$ & $0.74^{\star *}$ \\
\hline & $17-08-22$ & $-0.53^{\star \star \star}$ & $0.26^{\star \star \star \star \star \star}$ & $-0.30^{\star \star \star \star \star \star *}$ & $0.59^{\star \star \star}$ \\
\hline
\end{tabular}

\footnotetext{
${ }^{*} P \leq 0.001$

${ }^{\star \star} P \leq 0.01$.

${ }^{\star \star *} P \leq 0.05$

${ }^{* * * *} P \leq 0.1$

${ }^{\star \star \star \star \star \star \star} P \leq 0.5$

${ }^{* \star \star \star * \star} P \leq 0.99$.
} 
Table 19 PCCs for DBM and narrowband ASD-based VNIR VIs by growth (G) and sampling date (T). NDREI, Normalized Difference Red-Edge Index; NDVI, Normalized Difference Vegetation Index; OSAVI, Optimized Soil Adjusted Vegetation Index; RDVI, Renormalized Difference Vegetation Index; REIP, Red Edge Inflection Point.

\begin{tabular}{|c|c|c|c|c|c|c|}
\hline G & $\mathrm{T}$ & NDREI & NDVI & OSAVI & RDVI & REIP \\
\hline \multirow[t]{2}{*}{1} & $17-05-03$ & $0.94^{*}$ & $0.92^{*}$ & $0.88^{*}$ & $0.84^{*}$ & $0.94^{*}$ \\
\hline & $17-05-10$ & $0.95^{\star}$ & $0.94^{\star}$ & $0.97^{\star}$ & $0.96^{*}$ & $0.96^{\star}$ \\
\hline \multirow[t]{2}{*}{2} & $17-06-07$ & $0.83^{*}$ & $0.80^{*}$ & $0.77^{*}$ & $0.74^{\star \star}$ & $0.82^{*}$ \\
\hline & $17-06-20$ & $0.64^{\star \star *}$ & $0.57^{\star \star \star}$ & $0.52^{\star \star \star}$ & $0.48^{\star \star \star \star}$ & $0.66^{\star \star}$ \\
\hline \multirow[t]{3}{*}{3} & $17-08-02$ & $0.81^{*}$ & $0.81^{*}$ & $0.83^{*}$ & $0.83^{*}$ & $0.79^{*}$ \\
\hline & $17-08-09$ & $0.74^{\star \star}$ & $0.74^{\star \star}$ & $0.75^{\star \star}$ & $0.74^{\star \star}$ & $0.74^{\star *}$ \\
\hline & $17-08-22$ & $0.79^{*}$ & $0.80^{*}$ & $0.71^{\star *}$ & $0.64^{\star \star \star}$ & $0.81^{*}$ \\
\hline
\end{tabular}

${ }^{*} P \leq 0.001$

${ }^{\star \star} P \leq 0.01$.

${ }^{* \star *} P \leq 0.05$.

${ }^{* * * *} P \leq 0.1$

${ }^{\star \star * \star \star \star} P \leq 0.5$.

${ }^{\star \star \star \star \star \star} P \leq 0.99$

\section{Acknowledgments}

We thank Yara International ASA (Research Center Hanninghof) for funding the experiment, especially Dr. Jörg Jasper. We thank the Campus Klein-Altendorf staff for maintaining the experiment and our student assistants for their extensive help in the field. The authors declare no conflicts of interest.

\section{References}

1. Food and Agriculture Organization of the United Nations, "Challenges and opportunities for carbon sequestration in grassland systems. A technical report on grassland management and climate change mitigation," Integr. Crop Manag. 9, 55 (2010).

2. D. J. Gibson, Grasses and Grassland Ecology, Oxford University Press, Oxford (2009).

3. F. P. O'Mara, “The role of grasslands in food security and climate change," Ann. Bot. 110(6), 1263-1270 (2012).

4. J. Schellberg and E. Verbruggen, "Frontiers and perspectives on research strategies in grassland technology," Crop Pasture Sci. 65(6), 508-523 (2014).

5. A. M. O'Sullivan, W. F. O'Keeffe, and M. J. Flynn, "The value of pasture height in the measurement of dry matter yield," Irish J. Agric. Res. 26(1), 63-68 (1987).

6. G. Bareth and J. Schellberg, "Replacing manual rising plate meter measurements with low-cost UAV-derived sward height data in grasslands for spatial monitoring," $P F G-J$. Photogramm. Remote Sens. Geoinf. Sci. 86(3-4), 157-168 (2018).

7. N. Viljanen et al., "A novel machine learning method for estimating biomass of grass swards using a photogrammetric canopy height model, images and vegetation indices captured by a drone," Agriculture 8, 70 (2018).

8. J. E. López-Díaz and A. González-Rodríguez, "Measuring herbage mass by non-destructive methods: a review," J. Agric. Sci. Technol. A 1(7), 303-314 (2011).

9. M. Wachendorf, T. Fricke, and T. Möckel, "Remote sensing as a tool to assess botanical composition, structure, quantity and quality of temperate grasslands," Grass Forage Sci. $\mathbf{7 3}$, 1-14 (2017).

10. J. Schellberg et al., "Precision agriculture on grassland: applications, perspectives and constraints," Eur. J. Agron. 29(2-3), 59-71 (2008). 
11. W. R. Catchpole and C. H. Wheeler, "Estimating plant biomass: a review of techniques," Aust. J. Ecol. 17, 121-131 (1992).

12. M. A. Sanderson et al., "Estimating forage mass with a commercial capacitance meter, rising plate meter, and pasture ruler," Agron. J. 93, 1281-1286 (2001).

13. M. O'Donovan et al., "A comparison of four methods of herbage mass estimation," Irish J. Agric. Food Res. 41, 17-27 (2002).

14. D. J. Mulla, "Twenty five years of remote sensing in precision agriculture: key advances and remaining knowledge gaps," Biosyst. Eng. 114(4), 358-371 (2013).

15. C. Atzberger, "Advances in remote sensing of agriculture: context description, existing operational monitoring systems and major information needs," Remote Sens. 5(2), 949-981 (2013).

16. P. J. Pinter, Jr. et al., "Remote sensing for crop management," Photogramm. Eng. Remote Sens. 69(6), 647-664 (2003).

17. L. Serrano, I. Filella, and J. Penuelas, "Remote sensing of biomass and yield of winter wheat under different nitrogen supplies," Crop Sci. 40, 723-731 (2000).

18. C. Mundava et al., "Evaluation of vegetation indices for rangeland biomass estimation in the Kimberley area of Western Australia," ISPRS Ann. Photogramm. Remote Sens. Spat. Inf. Sci. II-7(October), 47-53 (2014).

19. M. Barrachina, J. Cristóbal, and A. F. Tulla, "Estimating above-ground biomass on mountain meadows and pastures through remote sensing," Int. J. Appl. Earth Obs. Geoinf. 38, 184-192 (2015).

20. S. Manfreda et al., "On the use of unmanned aerial systems for environmental monitoring," Remote Sens. 10, 641 (2018).

21. W. Maes and K. Steppe, "Perspectives for remote sensing with unmanned aerial vehicles in precision agriculture," Trends Plant Sci. 24(2), 152-164 (2019).

22. H. Aasen et al., "Quantitative remote sensing at ultra-high resolution with UAV spectroscopy: a review of sensor technology, measurement procedures, and data correction workflows," Remote Sens. 10(7), 1091 (2018).

23. I. Colomina and P. Molina, "Unmanned aerial systems for photogrammetry and remote sensing: a review," ISPRS J. Photogramm. Remote Sens. 92(June), 79-97 (2014).

24. J. Bendig et al., "Combining UAV-based plant height from crop surface models, visible, and near infrared vegetation indices for biomass monitoring in barley," Int. J. Appl. Earth Obs. Geoinf. 39, 79-87 (2015).

25. S. Brocks, "Estimating barley biomass with crop surface models from oblique RGB imagery," Remote Sens. 10(2), 268 (2018).

26. M. Schirrmann et al., "Monitoring agronomic parameters of winter wheat crops with low-cost UAV imagery," Remote Sens. 8, 706 (2016).

27. J. Geipel, J. Link, and W. Claupein, "Combined spectral and spatial modeling of corn yield based on aerial images and crop surface models acquired with an unmanned aircraft system," Remote Sens. 6(11), 10335-10355 (2014).

28. W. van Iersel et al., "Monitoring height and greenness of non-woody floodplain vegetation with UAV time series," ISPRS J. Photogramm. Remote Sens. 141, 112-123 (2018).

29. E. R. Hunt et al., "Acquisition of NIR-green-blue digital photographs from unmanned aircraft for crop monitoring," Remote Sens. 2(1), 290-305 (2010).

30. S. Candiago et al., "Evaluating multispectral images and vegetation indices for precision farming applications from UAV images," Remote Sens. 7(Vi), 4026-4047 (2015).

31. J. Geipel and A. Korsaeth, "Hyperspectral aerial imaging for grassland yield estimation," Adv. Anim. Biosci. 8(2), 770-775 (2017).

32. R. Ballesteros et al., "Onion biomass monitoring using UAV-based RGB," Precis. Agric. 19, 840-857 (2018).

33. E. Honkavaara et al., "Processing and assessment of spectrometric, stereoscopic imagery collected using a lightweight UAV spectral camera for precision agriculture," Remote Sens. 5(10), 5006-5039 (2013).

34. H. Aasen et al., "Generating 3D hyperspectral information with lightweight UAV snapshot cameras for vegetation monitoring: from camera calibration to quality assurance," ISPRS J. Photogramm. Remote Sens. 108(May 2016), 245-259 (2015). 
35. J. Yue et al., "Estimation of winter wheat above-ground biomass using unmanned aerial vehicle-based snapshot hyperspectral sensor and crop height improved models," Remote Sens. 9(7), 708 (2017).

36. R. Näsi et al., "Estimating biomass and nitrogen amount of barley and grass using UAV and aircraft based spectral and photogrammetric 3D features," Remote Sens. 10(7), 1082 (2018).

37. B. Reddersen, T. Fricke, and M. Wachendorf, "A multi-sensor approach for predicting biomass of extensively managed grassland," Comput. Electron. Agric. 109, 247-260 (2014).

38. N. Tilly, H. Aasen, and G. Bareth, "Fusion of plant height and vegetation indices for the estimation of barley biomass," Remote Sens. 7(9), 11449-11480 (2015).

39. T. Moeckel et al., "Fusion of ultrasonic and spectral sensor data for improving the estimation of biomass in grasslands with heterogeneous sward structure," Remote Sens. 9(1), 98 (2017).

40. T. Fricke, F. Richter, and M. Wachendorf, "Assessment of forage mass from grassland swards by height measurement using an ultrasonic sensor," Comput. Electron. Agric. 79(2), 142-152 (2011).

41. D. Wang et al., "Modeling aboveground biomass in Hulunber grassland ecosystem by using unmanned aerial vehicle discrete LiDAR," Sensors 17(1), 1-19 (2017).

42. S. D. Cooper et al., "Examination of the potential of terrestrial laser scanning and structurefrom-motion photogrammetry for rapid nondestructive field measurement of grass biomass," Remote Sens. 9, 531 (2017).

43. M. T. Schaefer and D. W. Lamb, "A combination of plant NDVI and LiDAR measurements improve the estimation of pasture biomass in tall fescue (Festuca arundinacea var. Fletcher)," Remote Sens. 8(2), 109 (2016).

44. G. Bareth et al., "Feasibility study of using non-calibrated UAV-based RGB imagery for grassland monitoring: case study at the Rengen Long-term Grassland Experiment (RGE), Germany," in Proc. 35. Annu. Meeting of the German Soc. for Photogramm., Remote Sens. and Geoinf., Cologne, pp. 55-62 (2015).

45. H. Zhang et al., "Estimation of grassland canopy height and aboveground biomass at the quadrat scale using unmanned aerial vehicle," Remote Sens. 10(6), 851 (2018).

46. E. Grüner, T. Astor, and M. Wachendorf, "Biomass prediction of heterogeneous temperate grasslands using an SfM approach based on UAV imaging," Agronomy 9(2), 54 (2019).

47. J. Forsmoo et al., "Drone-based structure-from-motion photogrammetry captures grassland sward height variability," J. Appl. Ecol. (February), 55, 2587-2599 (2018).

48. U. Lussem et al., "Feasibility study of directly georeferenced images from low-cost unmanned aerial vehicles for monitoring sward height in a long-term experiment on grassland," Grassl. Sci. Eur. 22, 354-356 (2017).

49. J. Bendig, A. Bolten, and G. Bareth, "UAV-based imaging for multi-temporal, very high resolution crop surface models to monitor crop growth variability," $P F G-J$. Photogramm. Remote Sens. Geoinf. Sci. 6, 551-562 (2013).

50. L. Roth and B. Streit, "Predicting cover crop biomass by lightweight UAS-based RGB and NIR photography: an applied photogrammetric approach," Precis. Agric. 19(1), 1-22 (2017).

51. A. M. Cunliffe, R. E. Brazier, and K. Anderson, "Ultra-fine grain landscape-scale quantification of dryland vegetation structure with drone-acquired structure-from-motion photogrammetry," Remote Sens. Environ. 183, 129-143 (2016).

52. A. Gitelson et al., "Novel algorithms for remote estimation of vegetation fraction," Remote Sens. Environ. 80, 76-87 (2002).

53. C. J. Tucker, "Red and photographic infrared linear combinations for monitoring vegetation," Remote Sens. Environ. 8(2), 127-150 (1979).

54. D. Woebbecke et al., "Color indices for weed identification under various soil, residue, and lighting conditions," Trans. ASAE 38(1), 259-269 (1995).

55. U. Lussem et al., "Evaluation of RGB-based vegetation indices from UAV imagery to estimate forage yield in grassland," ISPRS-Int. Arch. Photogramm. Remote Sens. Spat. Inf. Sci. XLII-3, 1215-1219 (2018).

56. R. Jannoura et al., "Monitoring of crop biomass using true colour aerial photographs taken from a remote controlled hexacopter," Biosyst. Eng. 129, 341-351 (2015). 
57. E. R. Hunt et al., "Evaluation of digital photography from model aircraft for remote sensing of crop biomass and nitrogen status," Precis. Agric. 6, 359-378 (2005).

58. A. Stevens and L. Ramirez-Lopez, "Prospectr: miscellaneous functions for processing and sample selection of vis-NIR diffuse reflectance data. $\mathrm{R}$ package version 0.1.3," $R$ package version 0.1.3, 2015, https://rdrr.io/cran/prospectr/.

59. S. Flynn, C. Dougherty, and O. Wendroth, "Assessment of pasture biomass with Normalized Difference Vegetation Index from active ground-based sensors," Agron. J. 100(1), 114-121 (2008).

60. A. Capolupo et al., "Estimating plant traits of grasslands from UAV-acquired hyperspectral images: a comparison of statistical approaches," ISPRS Int. J. Geo-Inf. 4(4), 2792-2820 (2015).

61. L. Vescovo et al., "New spectral vegetation indices based on the near-infrared shoulder wavelengths for remote detection of grassland phytomass," Int. J. Remote Sens. 33(7), 2178-2195 (2012).

62. J. W. Rouse et al., "Monitoring vegetation systems in the Great Plains with ETRS," in Third ETRS Symposium (NASA SP-351), S. Fraden, E. Marcanti, and E. Becker, Eds., Scientific and Technical Information Office, National Aeronautics and Space Administration, Washington, D.C., pp. 309-317 (1974).

63. J. L. Roujean and F. M. Breon, "Estimating PAR absorbed by vegetation from bidirectional reflectance measurements," Remote Sens. Environ. 51(3), 375-384 (1995).

64. G. Rondeaux, M. Steven, and F. Baret, "Optimization of soil-adjusted vegetation indices," Remote Sens. Environ. 55, 95-107 (1996).

65. G. Guyot and F. Baret, "Utilisation de la Haute Resolution Spectrale pour Suivre Létat des Couverts Vegetaux," in Spectral Signatures of Objects in Remote Sensing, T. D. Guyenne and J. J. Hunt, Eds., pp. 279-286, European Space Agency, Modane, France (1988).

66. A. Gitelson and N. Merzlyak, "Quantitative experiments estimation of chlorophyll-a using reflectance with autumn chestnut and maple leaves and spectra," J. Photochem. Photobiol. B Biol. 22(3), 247-252 (1994).

67. R Core Team, $R$ : A Language and Environment for Statistical Computing, R Foundation for Statistical Computing, Vienna (2013).

68. M. Kuhn et al., "Caret: classification and regression training," $R$ package version 6.0-81 (2018).

69. M. Kuhn, "Building predictive models in R using the caret package," J. Stat. Softwares 28(5), 1-26 (2008).

70. G. James et al., An Introduction to Statistical Learning, Springer, New York, Heidelberg, Dordrecht, London (2013).

71. J. Rasmussen et al., "Are vegetation indices derived from consumer-grade cameras mounted on UAVs sufficiently reliable for assessing experimental plots?" Eur. J. Agron. 74, 75-92 (2016).

Biographies of the authors are not available. 